\title{
Sentinel-1 time series for mapping snow cover and timing of snowmelt in Arctic periglacial environments: Case study from the Zackenberg Valley, Greenland
}

\author{
Sebastian Buchelt ${ }^{1}$, Kirstine Skov ${ }^{2}$, and Tobias Ullmann ${ }^{1}$ \\ ${ }^{1}$ Department Physical Geography, Institute of Geography and Geology, University of Wuerzburg, 97072 Wuerzburg, Germany \\ ${ }^{2}$ Department of Bioscience, Arctic Research Center, Aarhus University, 4000 Roskilde, Denmark \\ Correspondence: Sebastian Buchelt (sebastian.buchelt@uni-wuerzburg.de)
}

\begin{abstract}
Snow cover (SC) and timing of snowmelt are key regulators of a wide range of Arctic ecosystem functions. Both are strongly influenced by the amplified arctic warming and essential variables to understand environmental changes and their dynamics. This study evaluates the potential of Sentinel-1 (S-1) synthetic aperture radar (SAR) time series for monitoring SC and snowmelt with high spatiotemporal resolution to capture their understudied small-scale heterogeneity. We use 97 dual-polarized S-1 SAR images acquired over north-eastern Greenland in the interferometric wide swath mode from the years 2017 and 2018. Comparison of S-1 intensity against SC fraction maps derived from orthorectified terrestrial time lapse imagery indicates an increase of the SAR intensity before a decrease of SC fraction is observed. Hence, increase of backscatter is related to changing snowpack properties during the runoff phase as well as decreasing SC fraction. We here present a novel approach using backscatter intensity thresholds to identify start and end of snowmelt (SOS and EOS), perennial snow and wet/dry SC based on the temporal evolution of the SAR signal. Comparison of SC with orthorectified time lapse imagery indicate that HV polarization outperforms $\mathrm{HH}$ when using a global threshold. With a global configuration (Threshold: $4 \mathrm{~dB}$; polarization: HV), the overall accuracy of SC maps was in all cases above $75 \%$ and in more than half cases above $90 \%$ enabling a large-scale $\mathrm{SC}$ monitoring at high spatiotemporal resolution (20 m, 6 days) with high accuracy.
\end{abstract}

\section{Introduction}

\subsection{Snow in arctic environments}

Snow cover (SC) has been identified as an essential climate variable (GCOS-WMO, 2020) covering about 40 to $50 \%$ of the northern hemisphere during winter (Dietz et al., 2012; Rees, 2006; Tsai et al., 2019b). It plays an important role for various components of the Earth system like hydrology, ecology and climatology as well as global energy, water and carbon cycles due to the large seasonal variability in snow extent on the northern hemisphere (between 4 to 46 million $\mathrm{km}^{2}$ in summer and winter, respectively (Rees, 2006)) and the specific physical properties (Arslan et al., 2017; Box et al., 2019; Dietz et al., 2012; Pedersen et al., 2018). Its high albedo (0.8 to 0.9) compared to snow-free coverages strongly influences the energy balance. Moreover, its insulating properties limit heat exchange between soil and atmosphere and, thereby, regulate the seasonal active 
https://doi.org/10.5194/tc-2021-78

Preprint. Discussion started: 13 April 2021

(c) Author(s) 2021. CC BY 4.0 License.

\section{(c) (i)}

layer thickness (Rees, 2006; Tsai et al., 2019b). The snowpack plays an important role for water storage and supply (Dietz et al., 2012; Marin et al., 2020) and it is a key factor for arctic phenology, ecology and the distribution of flora (Assmann et al., 2019; Ide and Oguma, 2013; Kepski et al., 2017). On the one hand, the thermal insulation protects plants from frost damages and the snowpack provides water and, with it, nutrients for the plants. On the other hand, SC blocks the sunlight needed for photosynthetic activity. Further, plants are linking their metabolic activity directly to the timing of snowmelt (Assmann et al., 2019; Ide and Oguma, 2013; Kankaanpää et al., 2018; Kepski et al., 2017; Pedersen et al., 2018). However, the timing of snowmelt is highly variable in space and time and influenced by snow accumulation, redistribution, and ablation. The former two depend on the climatic conditions, e.g. latitudinal and altitudinal position and continentality, as well as on the local topography that affects transport of snow due to wind and gravitational redistribution. Thereby, snow is shifted from windward slopes, ridges, steep and high terrain to wind sheltered leeward slopes, sinks and low-lying terrain (Elberling et al., 2008; Farinotti et al., 2010; Lehning et al., 2008; Mott et al., 2018; Pedersen et al., 2016). Therefore, the redistribution effects generate a similar pattern of snow accumulation at the end of the winter primarily driven by the local topography, while the overall amount of snow depends on the amount of solid winter precipitation (Buus-Hinkler et al., 2006; Farinotti et al., 2010; Ide and Oguma, 2013; Kepski et al., 2017; Pedersen et al., 2018). Ablation is driven by temperature, turbulent fluxes and solar radiation (Mott et al., 2011, 2013), which, in combination with redistribution, leads to a high small-scale heterogeneity of SC during melt season (Mott et al., 2018). Knowledge about SC is important because it is decreasing with rising temperatures, resulting in a negative self-strengthening feedback between temperature and SC, which might partially drive the arctic amplification (Hock et al., 2019; Meredith et al., 2019; Rees, 2006). The decrease of SC duration and extent has been documented for the northern hemisphere over the last 40 years (Box et al., 2019; Brown and Robinson, 2011; Meredith et al., 2019)) and could have a negative impact on species richness (Niittynen et al., 2018), but changes on local scale do not indicate clear trends (e.g. Pedersen et al., 2016; Young et al., 2018). Moreover, Hock et al. (2019) state that knowledge about SC distribution is still limited, especially at small spatiotemporal scales.

\subsection{SAR remote sensing of snow}

As such, SC monitoring requires remote sensing products at very high spatial and temporal resolution. Until recently, freely available synthetic aperture radar (SAR) data could not fulfil these requirements; however, with the twin satellites of the Sentinel-1 (S-1) mission, SAR data becomes an attractive alternative (ESA, 2012; Marin et al., 2020) as this mission provides freely available C-Band SAR imagery at a spatial resolution of 10-20 m and with a six-day repeat cycle. While ground-based methods lack in spatial coverage, established SC mapping methods based on optical spaceborne earth observation suffer from reduced temporal resolution due to cloud coverage and sun illumination, e.g. during polar night (Dong, 2018; Portenier et al., 2020; Tsai et al., 2019b). SAR remote sensing can overcome these limitations, as it operates independent of sun illumination and atmospheric conditions (Marin et al., 2020; Tsai et al., 2019b; Ulaby et al., 2014). Previous studies applying SAR data have indicated its ability to detect wet snow, as liquid water in the snowpack decreases the dielectric constant leading to a higher absorption coefficient (Marin et al., 2020; Nagler and Rott, 2000; Ulaby et al., 2014). Hereby, the penetration depth decreases to a few centimetres and most of the signal is absorbed or reflected by the uppermost parts of the snowpack resulting 
https://doi.org/10.5194/tc-2021-78

Preprint. Discussion started: 13 April 2021

(c) Author(s) 2021. CC BY 4.0 License.

(c) (i)

in a strong decrease of the backscatter intensity (Marin et al., 2020; Ulaby et al., 2014). This effect is the basis for the bitemporal approach Nagler's method (Nagler and Rott, 2000), which compares backscatter intensities during snowmelt with reference satellite imagery acquired during snow-free or dry snow conditions (Nagler et al., 2016, 2018; Nagler and Rott, 2000; Snapir et al., 2019). However, this approach is only able to detect wet snow. More advanced methods additionally use digital elevation models (DEMs) (Nagler and Rott, 2000; Storvold and Malnes, 2004; Thakur et al., 2017) or optical remote sensing data (Nagler et al., 2018; Snapir et al., 2019; Thakur et al., 2018) to monitor dry snow. Nevertheless, these approaches cannot cover the small-scale heterogeneity of SC, because DEM-assisted approaches overestimate dry snow in steep terrain, while the inclusion of optical remote sensing data decreases the spatiotemporal resolution of the product (Solberg et al., 2010; Storvold and Malnes, 2004; Tsai et al., 2019b).

According to Tsai et al. (2019b), SAR time series have rarely been investigated for SC mapping as most studies apply their method only on a few scenes and mostly for one single year, hence not taking advantage of the abundant data available. So far, only Tsai et al. (2019a, c) developed a SC monitoring approach using the entire temporal information of a S-1 SAR time series by incorporating interferometric, polarimetric and backscatter intensity features as well as elevation and land cover information into a supervised classification approach. On the contrary, recent studies developed methods for snow depth estimation (Lievens et al., 2019) and snowmelt phase detection (Marin et al., 2020) based only on the distinct seasonal SAR backscatter signal of snow described in the following (Fig. 1): During winter, the liquid water content is close to $0 \%$ and the snowpack is nearly transparent to C-Band SAR. The returned signal is, therefore, predominantly scattered from ground surface underneath the snowpack with backscatter intensities similar to snow-free conditions (Marin et al., 2020; Nagler et al., 2016). With increasing temperatures snow is wetting leading to a strong decrease in backscatter intensity during the moistening and ripening phase (Marin et al., 2020; Nagler et al., 2016; Rees, 2006). In the last phase of snowmelt, which is called runoff, backscattering intensity increases again until an intensity level comparable to snow-free ground conditions is reached (Marin et al., 2020). This steady increase is not fully understood yet but three possible explanation are described by Marin et al. (2020): (i) the increasing surface roughness of the snowpack; (ii) an increased number and size of intrusions like ice lenses or snow grains; (iii) subpixel parts turning into snow-free state leading to patchy SC towards the end of the melting period causing mixed pixel signal response (Marin et al., 2020).

We here propose a novel method, which adapts Nagler's method (Nagler and Rott, 2000) to the seasonal evolution of the SAR signal using adaptive thresholds based on the seasonal minima of the SAR time series for fast, simple, but effective wet and dry SC mapping. With this new methodology, we can additionally derive start of snowmelt (SOS), end of snowmelt (EOS) and perennial snow patches. We validate EOS and SC derived from S-1 time series (2017 \& 2018) with a reference dataset, generated from time lapse photography available for the Zackenberg Valley (Northeast Greenland) and assess the interaction between SC fraction and backscatter intensity in detail. 


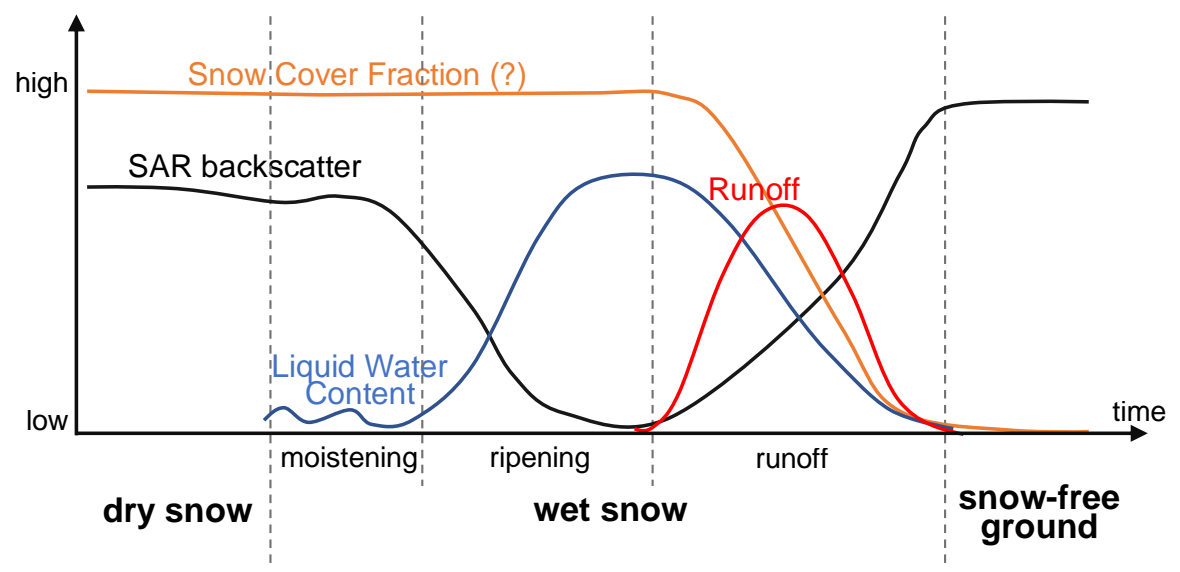

Figure 1. Schematic illustration of the seasonal evolution of synthetic aperture radar (SAR) backscatter intensity above snow with its phases of melt and relevant snow properties, i.e. liquid water content, runoff and snow cover fraction. This illustration is based on the findings of Marin et al. (2020) and Tsai et al. (2020) (modified from Tsai et al., 2020).

\section{Study site and datasets}

\subsection{Study area}

The Zackenberg research area (ZRA) is located in Northeast Greenland (Fig. 2a) approx. $40 \mathrm{~km}$ west of the outer coast and $70 \mathrm{~km}$ east of the inland ice sheet (Meltofte and Rasch, 2008). ZRA covers most parts of the Zackenberg valley floor and the surrounding slopes of Zackenberg Mountain (west) and Aucellabjerg (north and east) (Fig. 2c). The mean annual temperature in the valley is about $-9{ }^{\circ} \mathrm{C}$ and mean daily temperatures are usually above $0{ }^{\circ} \mathrm{C}$ from early June until mid-September (Hansen et al., 2008; Pedersen et al., 2018). The mean annual precipitation, with 80 to $85 \%$ falling as snow, is about $260 \mathrm{~mm}$ but varies largely from year to year $(150-400 \mathrm{~mm})$ (Hansen et al., 2008). Glacial ice occurs mostly at higher altitudes $(>1000 \mathrm{~m})$ due to low precipitation (Mernild et al., 2007). The radiation budget is dominated by polar night and day, which have a length of 89 days and 106 days, respectively (Pedersen et al., 2016). The climate is rather continental with high temperature fluctuations and low humidity due to the build-up of sea ice during winter in the Young Sound (Westergaard-Nielsen et al., 2017). The topographic setting and predominant northern winds during winter cause similar patterns of snow accumulation every year (Elberling et al., 2008; Hinkler et al., 2008; Kankaanpää et al., 2018; Pedersen et al., 2016). Vegetation formations below 200 m a.s.l. are dominated by small shrubs and grasses (Fig. 2b) (Elberling et al., 2008; Westergaard-Nielsen et al., 2017). With increasing altitude, the percentage of bare ground and rock increases, while above 600 a.s.l. only scarce vegetation is found (Buus-Hinkler et al., 2006; Elberling et al., 2008). The transition from SC to snow-free ground in ZRA begins in late May in years with low snow accumulation, but can be prolonged until early July in years with high snow accumulation and even until late July in the very extreme year of 2018 (López-Blanco et al., 2020). A peak in photosynthetic activity is usually reached in 

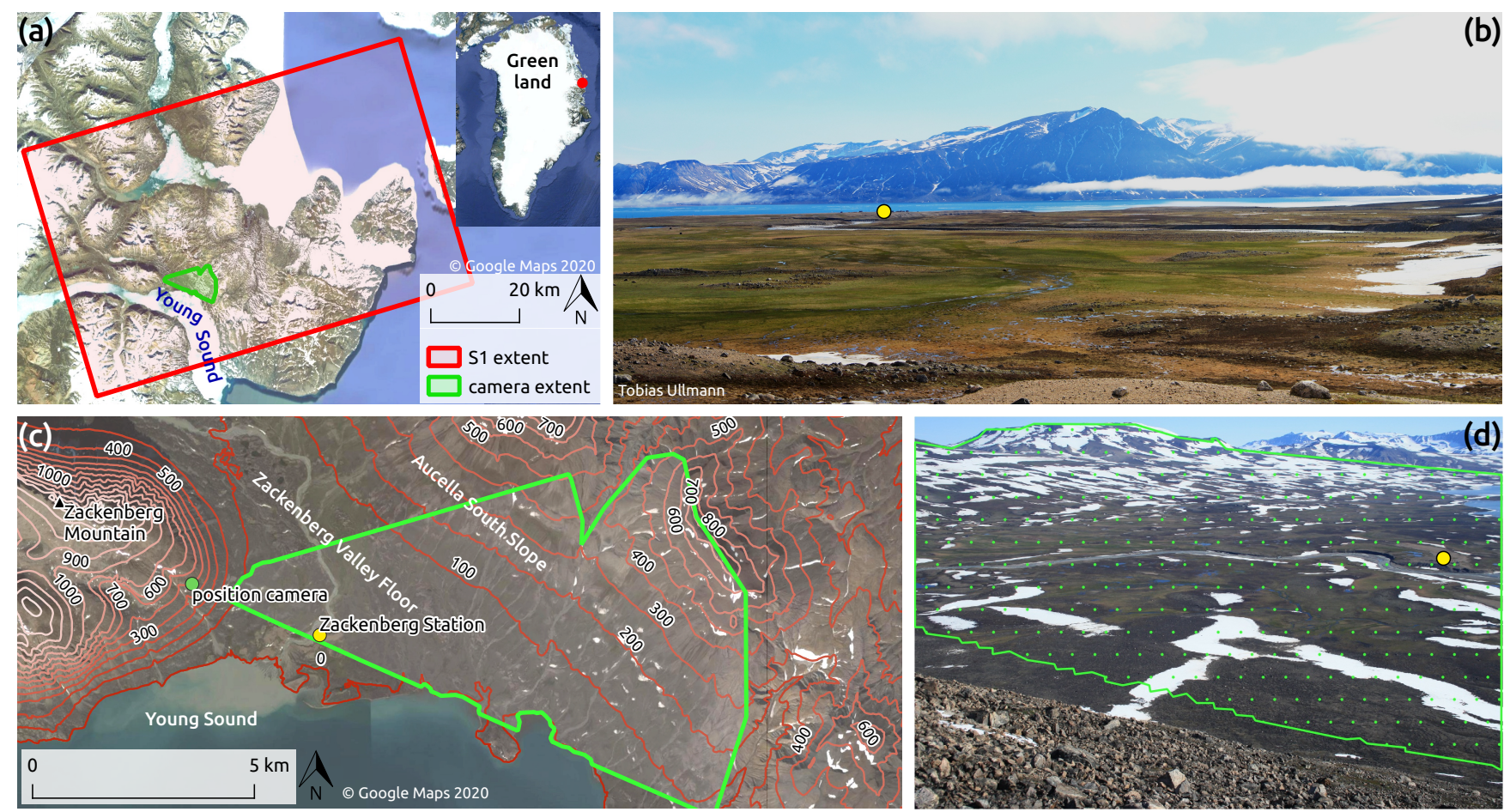

Figure 2. (a) Overview of Zackenberg study area and Sentinel-1 scene located in northeastern Greenland (see red dot in inlet). (b) Overview over valley floor looking from Aucella Slope southward to Young Sound and Zackenberg Station (yellow dot). Photo credit: Tobias Ullmann. (c) Study site with camera field of view and location of time lapse camera (green dot) and Zackenberg Research Station (yellow dot). (d) Master image of time lapse camera with used field of view and location of Zackenberg station (yellow dot). Background image from GeoBasis Zackenberg (Greenland Ecosystem Monitoring Secretariat, 2020).

late July to early August (Meltofte and Rasch, 2008; Westergaard-Nielsen et al., 2017) and the vegetation period usually ends in early September. Physical snow properties (e.g. SC fraction using time-lapse cameras) are measured regularly within the GeoBasis program (Skov et al., 2019; Westergaard-Nielsen et al., 2017).

\subsection{Datasets}

110 For this study, we investigated all S-1 single look complex (SLC) data Interferometric Wide swath mode (IW) acquisitions from the ascending orbit (relative orbit 74) over ZRA between the 1 January 2017 and the 31 December 2018 from the European Space Agency (ESA) Copernicus Open Access Hub (ESA, 2020a) and the Alaska Satellite Facility (Alaska Satellite Facility, $2020)$ at a repeat cycle of six days. As dual-polarimetric mode (HH + HV) started being operational for Greenland only from 21 May 2017 onwards, all previous acquisitions were neglected leading to a limited time series in 2017 (ESA, 2020b). In total, 38 scenes in the year 2017 and 59 scenes in the year 2018 were downloaded. The local acquisition time is 18:30 UTC. 
https://doi.org/10.5194/tc-2021-78

Preprint. Discussion started: 13 April 2021

(C) Author(s) 2021. CC BY 4.0 License.

\section{(c) (i)}

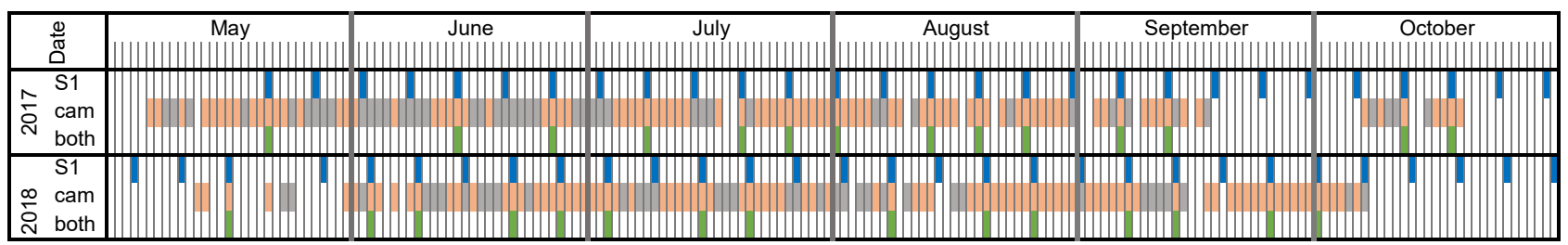

Figure 3. Acquisition dates of available data: blue: S-1; grey: camera time lapse imagery excluded due to bad quality; orange: used camera images; green: coinciding S-1 and camera dates, which were used for comparison and assessment of the products.

In ZRA, daily time lapse imagery of the central part of the Zackenberg Valley has been taken from the east facing slope of the Zackenberg mountain at solar noon since 1997 (Skov et al., 2019; Buus-Hinkler et al., 2006). The selected camera field of view excludes far distant ranges and close foreslopes. It covers about $45 \mathrm{~km} 2$ of the valley floor and the west-facing slopes of Aucellabjerg (see Fig. 2cd). The time lapse imagery from 2017 and 2018 was taken with a 10 Megapixel Canon EOS 1000D camera system and stored in a 24-bit JPG format (Skov et al., 2019; Westergaard-Nielsen et al., 2017). We manually excluded images of bad quality due to cloud cover, fog, or rain prior to the processing. In total 89 out of 137 images in 2017 and 91 out of 127 in 2018 were found useful (Fig. 3). The Greenland Ecosystem Monitoring program GeoBasis (Greenland Ecosystem Monitoring Secretariat, 2020) provide measures on SC fraction in ZRA derived from the above-mentioned camera (Skov et al., 2019; Westergaard-Nielsen et al., 2017), which is used as additional validation of the reference SC maps generated for this study.

Further, we used the ArcticDEM with a spatial resolution of $2 \mathrm{~m}$ (Porter et al., 2018; Noh and Howat, 2015; Polar Geospatial Center, 2020) for the processing of the S-1 scenes and the camera images, as it provides sufficiently high spatial resolution and accuracy needed for the calibration and orthorectification (Candela et al., 2017; Meddens et al., 2017). High resolution optical data from PlanetScope (Planet Team, 2019) satellites with a spatial resolution of $3 \mathrm{~m}$ are additionally used for the orthorectification process of the time lapse imagery. We selected a single cloud-free PlanetScope acquisition during the snowmelt season of 2018 with many distinguishable snow patches and patterns for which a corresponding time lapse camera image of good quality was available. The used scene (Satellite IDs: 1008 \& 1014) was acquired on the 12 August 2018 at about 11 AM local time with four spectral bands - red, green, blue and near infrared.

\section{Methodology}

\subsection{Sentinel-1 snowmelt and snow cover products}

The processing of S-1 products followed the workflow developed in Ullmann et al. (2019): The scenes were processed in IDL (version 8) and ENVI (version 5) using the functionalities of the ESA SNAP software (version 7). The processing included the application of the most recent orbit-file, split, calibration to backscatter coefficient $\beta 0$ and debursting. Thereafter, multilooking ( 1 in range, 3 in azimuth), speckle filtering using a boxcar filter with a window size of 3 by 3 pixels and calibration to 
backscatter coefficient $\gamma_{0}$ using the terrain flattening approach of Small (2011) with the ArcticDEM (Porter et al., 2018) was applied. The data were then terrain corrected using the Range-Doppler approach (Richards, 2009; Ulaby et al., 2014) and the ArcticDEM (Porter et al., 2018). Areas of shadow and layover were masked out. Datasets were processed to a spatial resolution of 20 by $20 \mathrm{~m}$ and all scenes were stacked and resampled to a common grid using bi-linear interpolation. The final product of S-1 preprocessing is the temporal stack of $\gamma_{0}$ backscatter intensities in decibel (dB) for both, $\mathrm{HV}$ and $\mathrm{HH}$ polarizations (Ullmann et al., 2019).

Our approach uses the $\gamma_{0}$ backscatter intensity time series as input and a simple set of thresholds, which are based on the characteristic seasonal backscatter behaviour above snow, to detect not only wet SC, but also (i) identify day of year (DOY) of start and end of the snowmelt (SOS/EOS), (ii) detect permanently snow-free areas and perennial snow patches and (iii) derive a SC map of wet and dry snow (Fig. 4). This characteristic temporal pattern is described by Marin et al. (2020) and Lievens et al. (2019) as a strong decrease in intensity in early spring followed by an increase in intensity during melt in late spring and summer. To detect the seasonal development of intensities, we compute the seasonal pixel-wise backscatter minimum $\min \left(\gamma_{0}\right)$ during the melt period (1 March - 31 August) as an adaptive reference. Thereafter, $S O S_{S-1}$ is determined (Eq. (1)) as the day of year (DOY), where the backscatter intensity $\left(\gamma_{0}\right)$ reaches the seasonal minimum $\min \left(\gamma_{0}\right)$ (i.e. in accordance with runoff phase detection of Marin et al. (2020)):

$S O S_{S-1}(x, y)= \begin{cases}D O Y & , \text { if } \gamma_{0}(x, y, D O Y)=\min \left(\gamma_{0}\right) \\ -1 & , \text { otherwise }\end{cases}$

Following $S O S_{S-1}, E O S_{S-1}$ is determined as the DOY, where the backscatter exceeds the seasonal minimum $\min \left(\gamma_{0}\right)$ by more than a user-defined threshold $t$ (Eq. (2)). Two further conditions are applied to filter events of melting followed by a freeze up of the snowpack, as these events cause a similar temporal evolution of the backscatter signal and, therefore, could lead to false detection: (i) In order to filter short-term snowpack refreeze events during the melt, the exceeding of $t$ must apply for three consecutive acquisitions (Eq. (2)). (ii) If backscatter values with less than $2 \mathrm{~dB}$ difference to the seasonal minimum are observed after a detected EOS and during early melt season (before 1 July), the pixel is considered as wet snow and a new EOS will be searched. Thereby, we filter early season short-term melt events followed by a refreeze of the snowpack. A pixel is classified as permanently snow-free, if no distinct temporal signal is found and the backscatter does not exceed the threshold $t$ for three consecutive acquisitions (Eq. (2)).

$\operatorname{EOS}_{S-1}(x, y)= \begin{cases}\text { first } D O Y & , \text { where } \gamma_{0}(x, y, D O Y)>\left(\min \left(\gamma_{0}\right)+t\right)(\text { three consecutive times }) \\ \text { permanently snow-free } & , \text { otherwise }\end{cases}$

Due to the high arctic environment in ZRA, perennial snow patches can occur. However, the algorithm presented in Eq. (2) to find EOS can only detect the end of the wet snow status, but cannot distinguish, whether the status changes to a snow-free or back to a dry-snow state. Therefore, we implement an additional condition to identify perennial snow patches based on the following assumption: Perennial snow has undergone several melt- and refreeze-cycles and has strong structural similarity to firn. Consequently, firn contains large snow grains and ice lenses that act as targets causing strong backscattering, especially 
https://doi.org/10.5194/tc-2021-78

Preprint. Discussion started: 13 April 2021

(c) Author(s) 2021. CC BY 4.0 License.

(c) (i)

volume scattering (Marin et al., 2020; Nagler and Rott, 2000). Therefore, the HV backscattering intensity in autumn and early winter, once snowpack is completely refrozen, should be much higher than in areas with snow completely melted and now covered by new snow with small grains. Visual assessment of the HV backscatter intensity confirms that this effect is occurring in the ZRA. Accordingly, pixels are classified as perennial snow, if their maximum HV backscattering $\max \left(\gamma_{0_{-} H V}\right)$ in autumn (1 October -31 December) exceeds $\min \left(\gamma_{0}\right)$ by $9 \mathrm{~dB}$ and the detected EOS is after 15 August (i.e. DOY 227) (Eq. (3)). The threshold of $9 \mathrm{~dB}$ is set in accordance with our observations that HV snow-free summer intensity does not exceed the seasonal minimum by more than this value.

$E_{\text {ES_final }}(x, y)= \begin{cases}\text { perennial snow } & \text {,if }\left(\begin{array}{c}\max \left(\gamma_{0 \_H V}\right)>\left(\min \left(\gamma_{0}\right)+9\right) \text { and } \\ \operatorname{EOS}_{(S-1)}(x, y)>227\end{array}\right) \\ \operatorname{EOS}_{(S-1)}(x, y) & \text {, otherwise }\end{cases}$

As a final step, the following Eq. (4) is used to derive SC maps from the EOS, the permanently snow-free and the perennial

180 snow products:

$S C_{-} D O Y_{S-1}(x, y)= \begin{cases}0 \text { (no-snow) } & \text {, if } D O Y \geq E O S_{-} f_{i n a l}-1(x, y) \text { or permanently snow-free } \\ 1 \text { (snow-covered) } & \text {, if } D O Y<E O S_{-} f_{i n a l}{ }_{S-1}(x, y) \text { or perennial snow }\end{cases}$

The resulting binary SC map at a specific DOY is 1 (snow-covered) or 0 (no-snow), if the DOY is before or after EOS, respectively. Optionally, further information on the snow status can be derived from the SOS. The SC is dry or wet, if the selected DOY is before or after SOS, respectively. For the further assessment of the S-1 SC products, the separation of wet and dry snow is neglected, as the terrestrial camera is not able to detect SOS.

\subsection{Time lapse imagery snowmelt and snow cover products}

Orthorectified SC maps are generated from time lapse camera images to validate the S-1 EOS and SC products (Fig. 4): (i) All time lapse camera images are aligned to the master image (12 August 2018) using discrete fourier transformation (implemented in the python package imreg_dft (Týč and Gohlke, 2014)). (ii) The stacked images are classified using the histogram minimum thresholding approach of Salvatori et al. (2011) in the following way: All pixel above and below the minimum of a bimodal histogram distribution are assigned as snow-covered and no-snow, respectively. However, we use the brightness histogram instead of the blue band to avoid misclassification of lakes and ponds reflecting the sky (e.g. like Westergaard-Nielsen et al., 2017). (iii) The master image is then orthorectified using the python package georef_webcam (Buchelt, 2020) based on the approaches of Corripio (2004), Härer et al. (2016) and Portenier et al. (2020). The ArcticDEM (Porter et al., 2018) is used for the projection and ground control points (GCPs) of remarkable landscape features are derived from same-day high-resolution PlanetScope imagery to optimize the orthorectification procedure resulting in a projection with high geospatial accuracy. (iv) Thereafter, the projected master is coregistered to the PlanetScope image with additional GCPs. (v) Based on the georeferenced master, all aligned and classified images are projected to SC maps in the coordinate system of S-1 with a spatial resolution of $2.5 \mathrm{~m}$ and then aggregated to $20 \mathrm{~m}$ resolution by calculating the SC fraction (SC_Fraction $\left.{ }_{D O Y}\right)$. 
https://doi.org/10.5194/tc-2021-78

Preprint. Discussion started: 13 April 2021

(c) Author(s) 2021. CC BY 4.0 License.

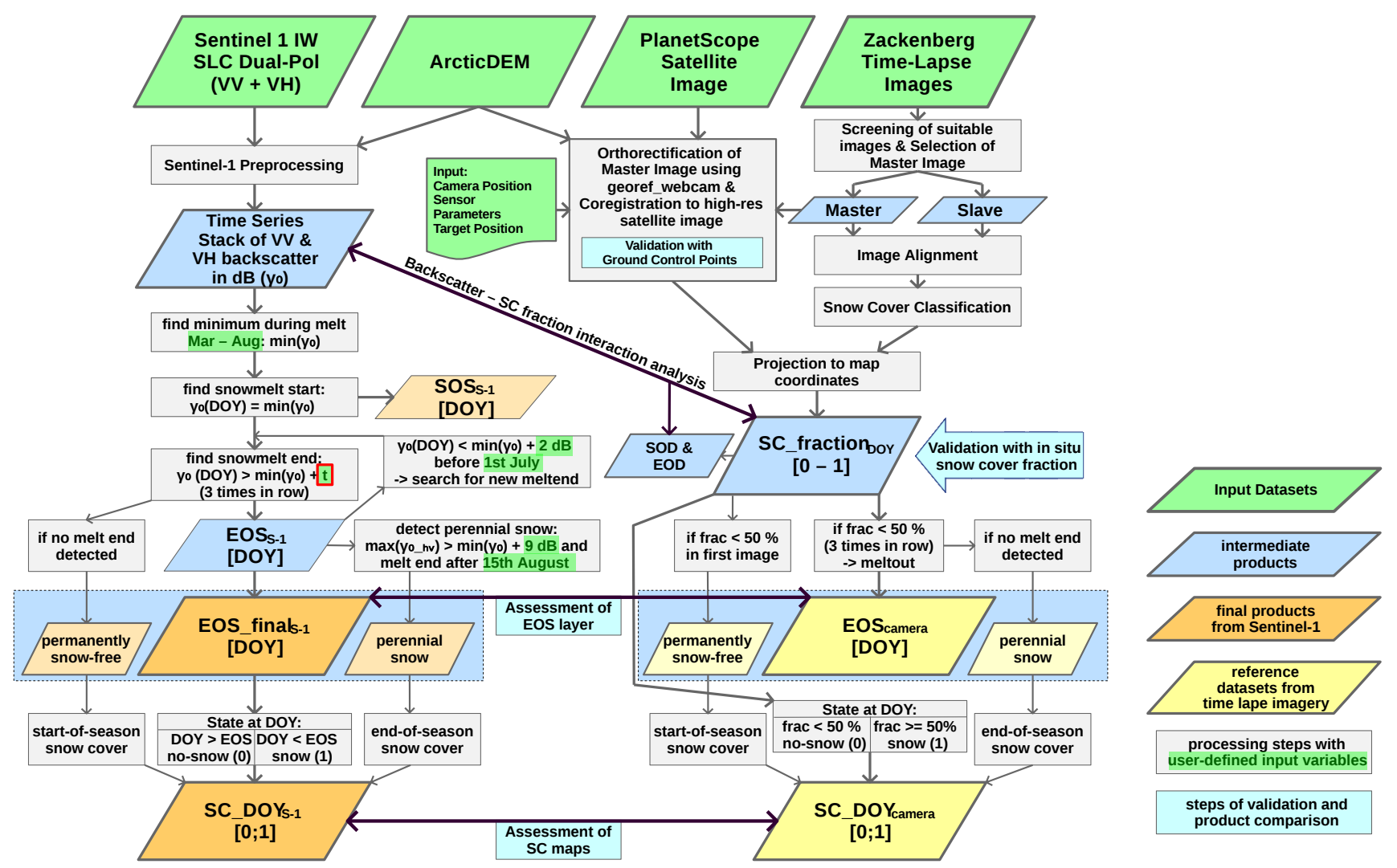

Figure 4. Workflow chart of proposed approach to detect snow cover (SC) and timing of snowmelt as start/end of snowmelt (SOS/EOS). EOS, permanently snow-free areas and perennial snow are visualized together as so-called melt layer (Fig. 9), whereas analysis is conducted separately. SOD/EOD: start/end of snow cover decrease, i.e. last DOY, where SC fraction is at $100 \%$ and first DOY, where SC fraction reaches $0 \%$, respectively. SOD and EOD are used for the backscatter - SC fraction interaction analysis.

For comparison with the S-1 products, permanently snow-free areas, perennial snow patches and EOS are derived from the SC fraction map using Eq. (5) (see also Fig. 4):

$\operatorname{EOS}_{\text {camera }}(x, y)= \begin{cases}\text { permanently snow-free } & \text {, if } S C_{-} \text {Fraction }_{D O Y_{-} 1}<0.5 \\ \operatorname{EOS}_{(S-1)}(x, y) & \text {, where } S C_{-} \text {Fraction }_{D O Y}<0.5 \text { (three consecutive times) } \\ \text { perennial snow } & \text {, otherwise }\end{cases}$

(i) Pixels, which are less than $50 \%$ snow covered in the first observation in spring $\left(S_{-}\right.$Fraction $\left._{D O Y_{-} 1}\right)$, are classified as permanently snow-free, whereas (ii) perennial snow are at least $50 \%$ snow covered in all orthorectified SC fraction maps. (iii)

EOS is determined for the remaining area as the first of three consecutive dates, where SC fraction falls below $50 \%$. Besides, (iv) Binary SC maps ( $S C \_D O Y_{\text {camera }}$ ) for validating S-1 SC maps are generated using the boundary condition that pixels 
https://doi.org/10.5194/tc-2021-78

Preprint. Discussion started: 13 April 2021

(c) Author(s) 2021. CC BY 4.0 License.

(c) (i)

have to be more than $50 \%$ snow covered in order to be classified as snow. (v) Further, DOY of start and end of SC decrease (SOD/EOD) are defined for each pixel as the last observation with $100 \%$ SC fraction and the first observation with $0 \%$ SC fraction, respectively. SOD and EOD are used for the backscatter - SC fraction interaction analysis (see Fig. 4).

We tested the accuracy of the orthorectification procedure using 25 GCPs to assure the correct location of the projected maps (Fig. 5b). The root mean square error (RMSE) of the orthorectification was $9.4 \mathrm{~m}$ and, therefore, less than one S-1 pixel (20 m). Besides, SC fraction maps from the time lapse imagery are validated with not orthorectified in situ data which used the same time lapse images as source (Greenland Ecosystem Monitoring Secretariat, 2020; Skov et al., 2019; Westergaard-Nielsen et al., 2017) to assure that the alignment, classification and orthorectification of the time lapse imagery do not induce errors in the temporal evolution of SC (Fig. 5a). The correlation of in situ SC fraction and mean SC fraction of the orthorectified SC fraction maps is tested by calculating the coefficient of determination $\left(\mathrm{R}^{2}=0.98\right)$ and the RMSE $(=3.7 \% \mathrm{SC}$ fraction $)$. With such high geolocation accuracy and high agreement in reproducing in situ SC fraction, we can assure minimized systematic errors in the generated SC fraction maps (SC_Fraction ${ }_{D O Y}$ ). The advantage compared to state-of-the-art validation procedures based on other satellite data is the high spatiotemporal resolution of the generated reference product ( $2.5 \mathrm{~m}$ with a temporal resolution of 1 - 10 days dependent on weather conditions). Thereby, we can evaluate the response of the SAR signal directly to changes in small-scale SC and the SC fraction.

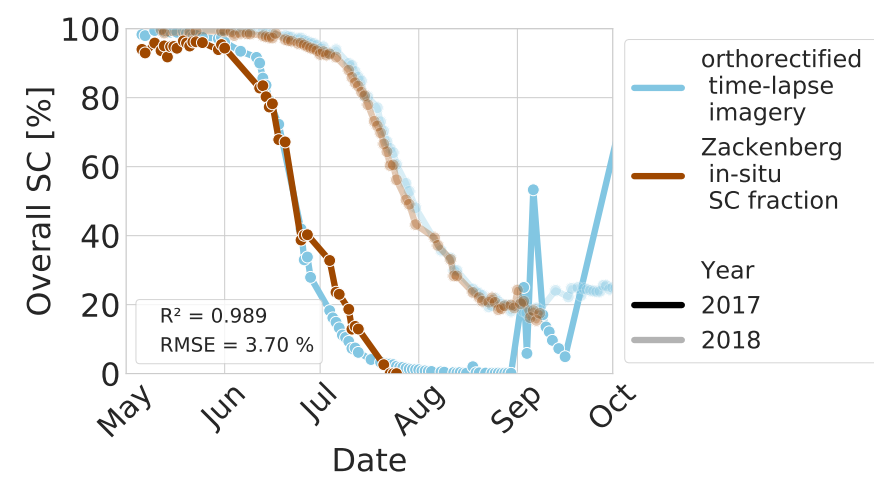

(a)

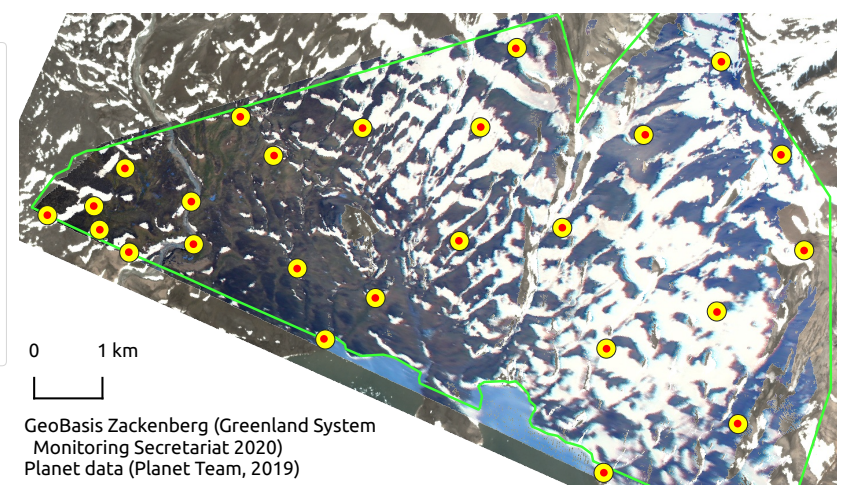

(b)

Figure 5. (a) Seasonal evolution of snow cover (SC) deducted from the orthorectified time lapse imagery compared with Zackenberg in situ snow cover fraction data. Their level of correlation is represented by $\mathrm{R}^{2}$ and RMSE. (b) Orthorectified master image and PlanetScope scene in the background with their respective ground control points (GCPs). The centre of the yellow dot indicates the projected location of the GCP, while the red dot shows the true location of the GCP. The distance between both is the orthorectification error $(\mathrm{RMSE}=9.4 \mathrm{~m})$. 
https://doi.org/10.5194/tc-2021-78

Preprint. Discussion started: 13 April 2021

(c) Author(s) 2021. CC BY 4.0 License.

\section{(c) (i)}

\subsection{Evaluation and assessment of the products}

\subsubsection{Backscatter - Snow cover fraction interaction analysis}

The development of S-1 backscatter intensity is compared to the SC fraction data derived from the time lapse imagery $\left(S C_{-}\right.$Fraction $\left._{D O Y}\right)$. We use the SC fraction derived from the time lapse imagery as an indicator to examine the timing of backscatter increase. We select all S-1 pixels with sufficient spatial data coverage by the time lapse imagery and include only areas which cover the entire snowmelt evolution during time-lapse imagery observation. Thus, areas with SOD before 1 June and EOD after 15 August are excluded from analysis. Original S- $1 \gamma_{0}$ intensity data (in dB) as well as intensities, which were rescaled from 0 (melt season minimum $\min \left(\gamma_{0}\right)$ intensity) to 1 (mean snow-free summer intensity) are compared to same-day SC fraction data of the time lapse imagery. Areas with $100 \%$ and $0 \% \mathrm{SC}$ fraction were further segmented according to the temporal distance to SOD and EOD, respectively.

\subsubsection{Assessment of product accuracy dependent on selected threshold and polarization}

According to our observations, the selection of polarization and threshold $t$ (Eq. (2)) is crucial for the accuracy of the S-1 snow products and using the standard threshold ( 2 to 3 dB in Nagler's method (Nagler and Rott, 2000; Nagler et al., 2016; Snapir et al., 2019)) might not be suited. Therefore, we investigated a threshold range from 2 to $8 \mathrm{~dB}$ for $\mathrm{HV}$ and from 3 to $10 \mathrm{~dB}$ for HH polarization. For each configuration, the accuracy of the SC maps (SC_DOY $Y_{-1} ; S C \_D O Y_{\text {camera }}$ ) was assessed in the following way: The assessment is based only on same-day S-1 acquisitions and orthorectified time lapse imagery to avoid errors due to temporal offsets (see used dates marked in green in Fig. 3). Acquisitions after 1 September are excluded from all analysis as our approach using the EOS to derive SC is not capable of detecting new snowfall events in autumn. The datasets of permanently snow-free areas and perennial snow patches are included in the SC accuracy analysis as follows: The class permanently snow-free is converted to SC at the start of the season with permanently snow-free pixels assigned as no-snow, and not permanently snow-free pixels as snow-covered. The perennial snow class is handled likewise as SC at the end of the season with perennial areas assigned as snow-covered and not perennial areas as no-snow. We calculate confusion matrix metrics (true positive (TP), true negative (TN), false positive (FP) and false negative (FN) rates as well as overall accuracy) for these SC maps for the selected view-field of the camera (Fig. 2c) and derive the receiving operator characteristic (ROC) from the overall TP and FP rate. Further analysis is carried out for the global polarization-threshold configuration with the best ROC (highest TP rate + lowest FP rate) and is conducted with the same reference used for identifying this configuration: (i) The temporal evolution of the confusion matrix metrics is assessed. (ii) We compare the EOS layers based on the areas, where the S-1 product $\left(E O S \_f_{i n a l}\right.$ S-1 $)$ and the georeferenced time lapse imagery (EOS $S_{\text {camera }}$ ) detect an EOS, by calculating $\mathrm{R}^{2}$, RMSE and mean absolute error (MAE). (iii) We calculate the difference in EOS DOY between the S-1 product and the orthorectified time lapse imagery for 2017 and 2018 together and examine the percentage of pixels covered at the same date as well as within different time ranges of less than $3( \pm 2), 6( \pm 5)$ and $12( \pm 11)$ days. The former gives the percentage of pixels, which were assigned to the temporally closest S-1 acquisition, the latter two correspond to one or two S-1 revisit cycles, respectively. (iv) Additionally, mean and median of the difference dataset are calculated. 
https://doi.org/10.5194/tc-2021-78

Preprint. Discussion started: 13 April 2021

(c) Author(s) 2021. CC BY 4.0 License.

(c) (i)

\section{Results}

\subsection{Interaction between backscatter increase and snow cover fraction}

We assess the distinct seasonal backscatter behaviour of S-1 over snow in ZRA in comparison to the SC fraction maps based on the orthorectified time lapse imagery $\left(S C_{-}\right.$Fraction $\left.{ }_{D O Y}\right)$. The backscatter intensity shows similar trends in both years and both polarizations. Before the SOD, backscatter intensity is rather low, reaching a minimum about 10 to 30 days before the SOD (Fig. 6a). In 2018 we observe a longer period of very low backscatter values (20 - 30 days), whereas this period is very short (5 - 10 days) in 2017. A sharp increase in intensity within the last $10-15$ days before SOD (Fig. 6ab) is observed for both years. Neglecting the logarithmic scaling of intensity in the rescaled backscatter intensity, we observe an increment from about +0.2 above the seasonal minimum to +0.5 to +0.6 above the seasonal minimum before SOD (Fig. $6 \mathrm{~b})$. The remaining increase to 1 (mean snow-free summer backscatter intensity) occurs mostly during the decrease of SC fraction (Fig. 6bc). The comparison of the absolute HH and HV intensities show differences (Fig. 6a). With HH polarization, a higher overall intensity and a larger difference between seasonal minimum and mean snow-free intensity is observed compared to HV. This difference is lower in 2017 than in 2018 due to higher backscatter minima (Fig. 6a). The rescaled intensities are stable for both years and polarizations and we observe a linear increase of rescaled backscatter with increasing SC fraction (Fig. 6c).

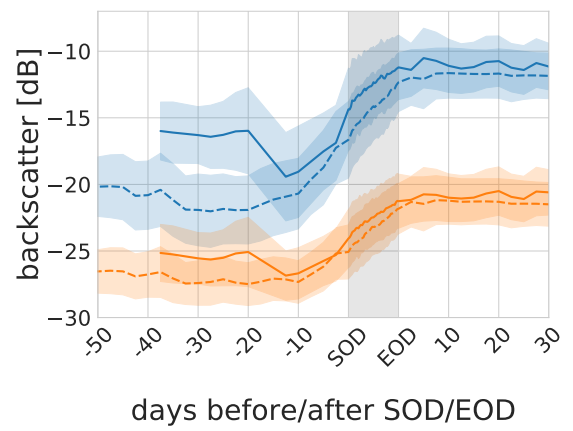

(a)

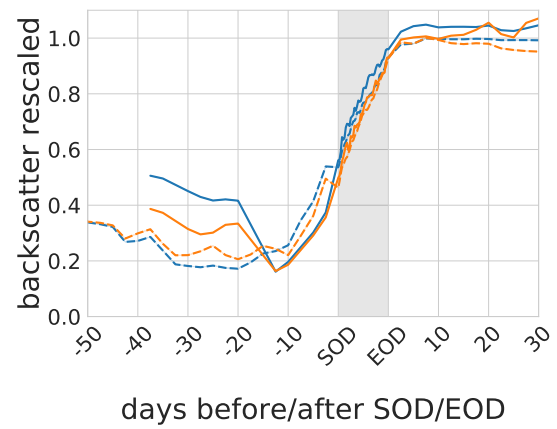

(b)

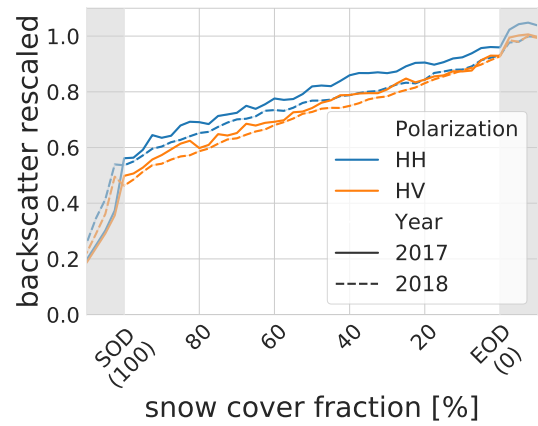

(c)

Figure 6. Development of Sentinel-1 backscatter intensity over the melting season compared to same-day snow cover (SC) fraction from orthorectified time lapse imagery $\left(S C_{-}\right.$Fraction $\left._{D O Y}\right)$. Negative days indicate the number of days before the first observable decrease in SC fraction (SOD - start of decrease). Positive days indicate the number of days after the observed snow cover fraction has reached $0 \%$ (EOD - end of decrease). The x-axis range (grey area) between SOD and EOD in (a) and (b) is modified to the observed average period between these dates (10 days) and does not represent the actual time range. (a) Seasonal development of absolute backscatter intensities $\left(\gamma_{0}\right)$ with standard deviation and (b) of rescaled intensities ( 0 : seasonal backscatter minimum $\min \left(\gamma_{0}\right) ; 1$ : mean snow-free summer backscatter intensity). (c) Close view on the development of rescaled backscatter between SOD and EOD during the decrease of SC fraction. 
https://doi.org/10.5194/tc-2021-78

Preprint. Discussion started: 13 April 2021

(c) Author(s) 2021. CC BY 4.0 License.

(c) (i)

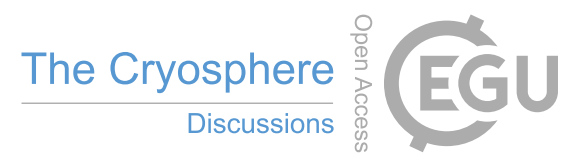

\subsection{Selection of threshold and polarization for Sentinel-1 snow products}

We assessed the SC evolution for each threshold $t$ and polarization to identify the parameter configuration that best fits the $\mathrm{SC}$ evolution in the orthorectified time lapse imagery (Fig. 7). For the determination of $t$, two opposite developments influence the accuracy of the resulting datasets: The higher $\mathrm{t}$, the more areas are mistakenly classified as permanently snow-free (Fig. 8a), as intensities of these locations do not exceed the defined threshold. In contrast, EOS is detected better using higher t, whereas low $t$ values cause a negative offset and EOS is detected earlier than observed (Fig. 8b). The constant increase of the intensity during the melt period causes this earlier detection of EOS with lower $t$ values. Thereby, higher values of $t$ result in an underestimation of SC in the early melt period, whereas lower values of $t$ lead to an underestimation of SC during the later melt period (Fig. 7). New SC due to snowfall events in autumn is not detectable by the proposed approach (Fig. 7).

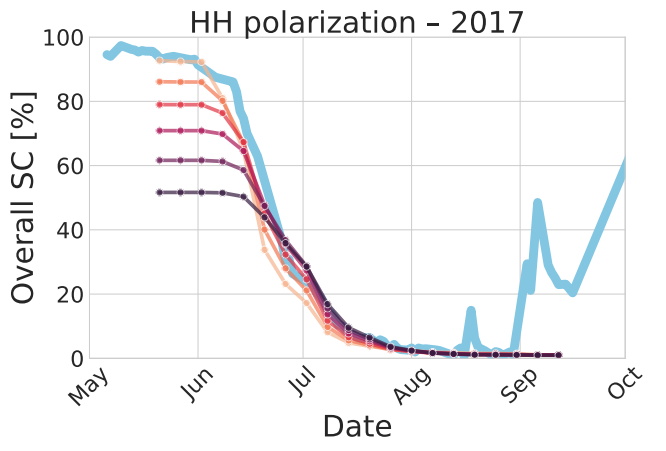

(a)

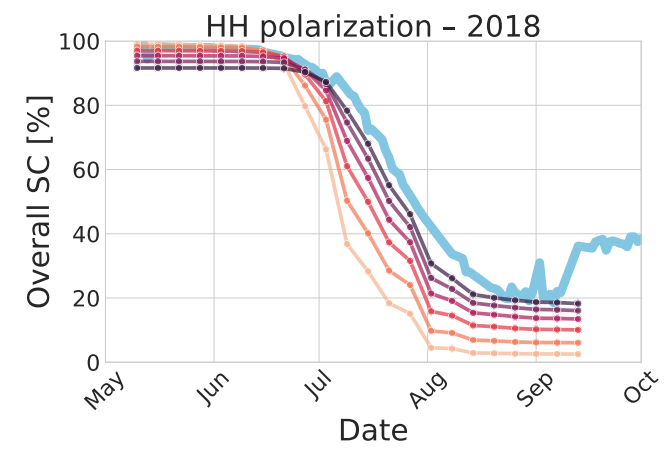

(d)

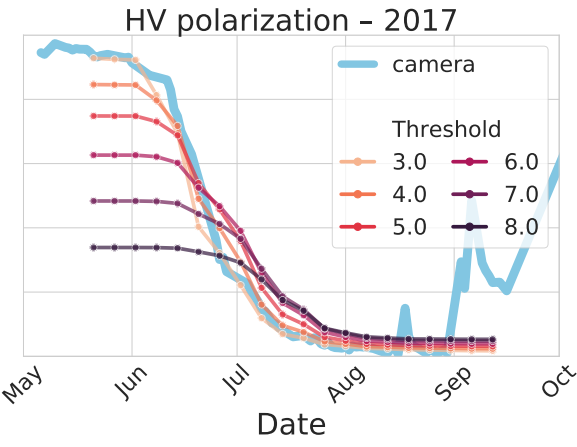

(b)

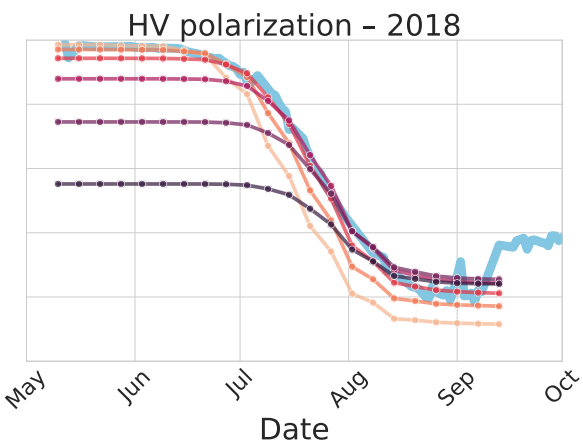

(e)

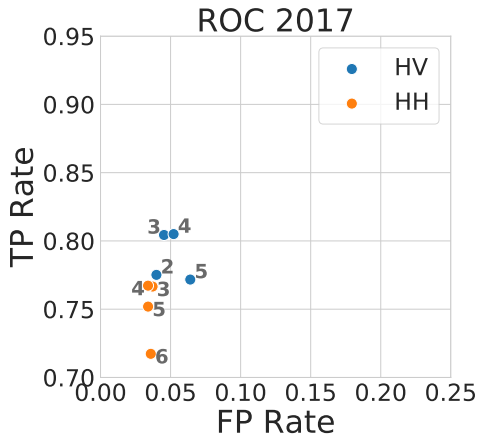

(c)

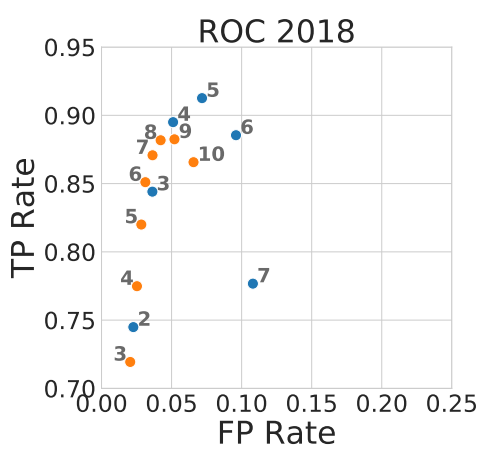

(f)

Figure 7. (a,b,d,e) Temporal development of overall snow cover (SC) of the Sentinel-1 product ( $\left.S C_{-} D O Y_{S-1}\right)$ with different thresholds and polarizations compared to orthorectified time lapse imagery $\left(S C_{-} D O Y_{\text {camera }}\right)$. Autumn $\mathrm{SC}$ is not detected by the proposed approach as only the seasonal decrease of SC is observable. (c,f) Receiver operator characteristic (ROC) derived from the overall true positive (TP) rates and false positive (FP) rates of the SC maps of (c) 2017 and (f) 2018 based on same-day S-1 acquisitions and orthorectified time lapse imagery. The used threshold is depicted as label next to each point. 
https://doi.org/10.5194/tc-2021-78

Preprint. Discussion started: 13 April 2021

(c) Author(s) 2021. CC BY 4.0 License.

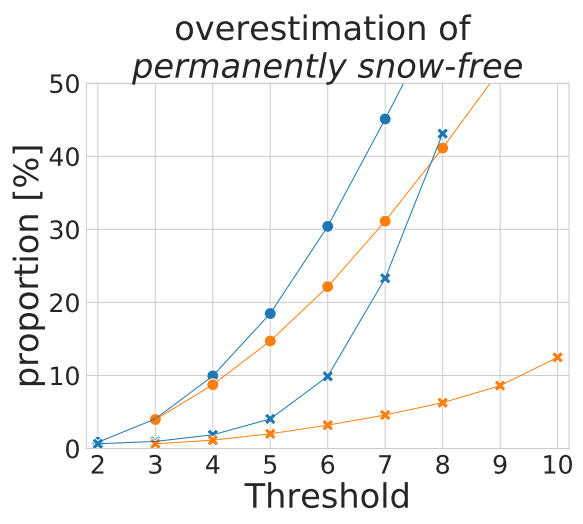

(a)

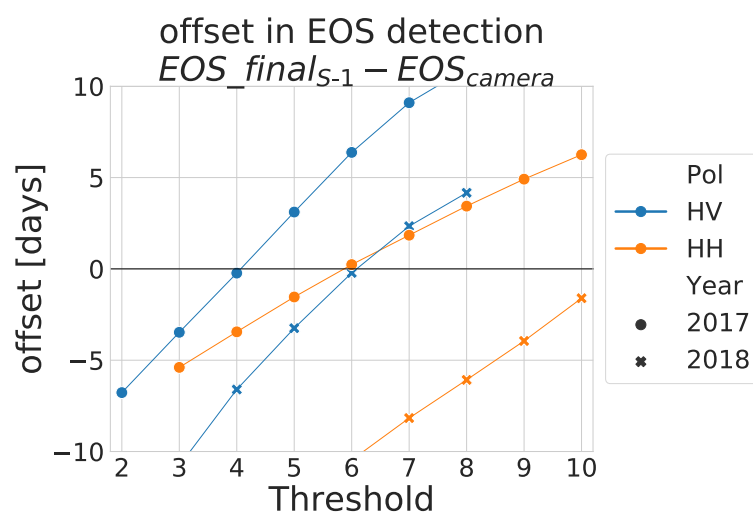

(b)

Figure 8. The key snow cover (SC) mapping accuracy parameters influenced by the threshold and polarization setting are (a) overestimation of permanently snow-free areas for higher thresholds leading to an underestimation of SC in early melt season and (b) a negative offset in mean EOS for low thresholds leading to underestimation of SC in late melt season.

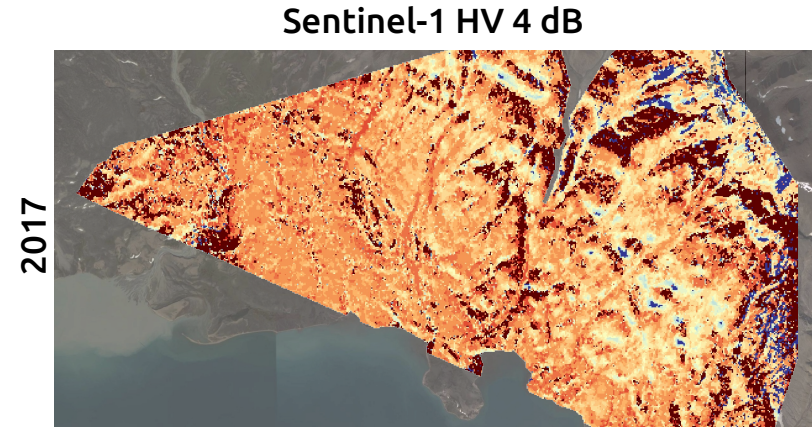

(a)

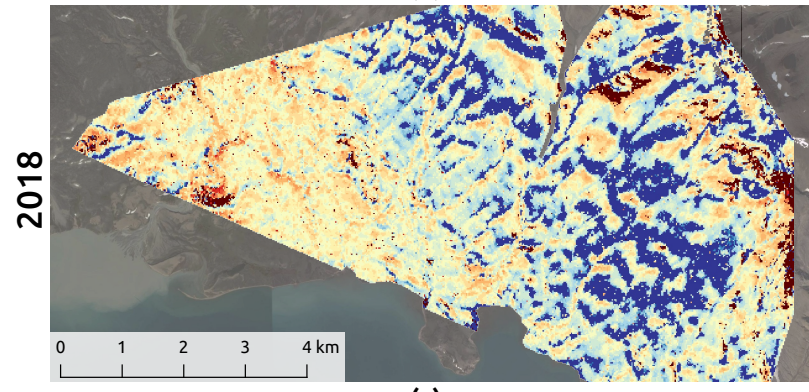

(c)

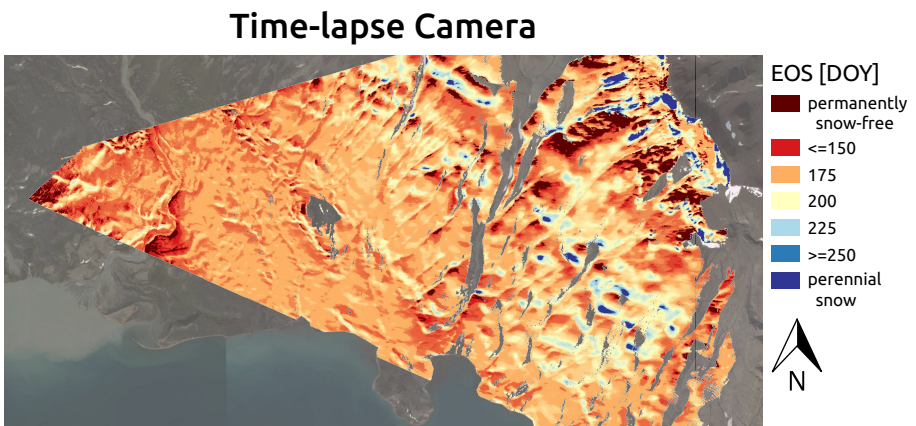

(b)

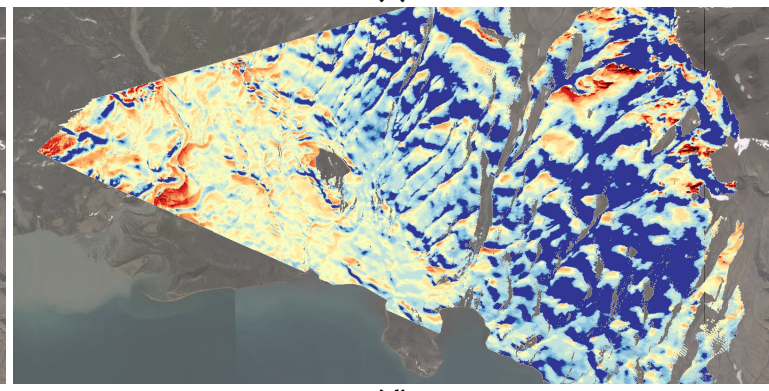

(d)

Figure 9. Melt layers (composites of day of year (DOY) for end of snowmelt (EOS), permanently snow-free areas and perennial snow patches) produced by the global parameter configuration (polarization: HV; threshold $t: 4 \mathrm{~dB}$ ). A subset of the generated S-1 product with 20 $m$ resolution bounded by the camera field of view is shown: (a) 2017 and (c) 2018. For comparison the corresponding composite generated from time lapse imagery with 2.5 m resolution are mapped: (b) 2017 and (d) 2018. 
https://doi.org/10.5194/tc-2021-78

Preprint. Discussion started: 13 April 2021

(c) Author(s) 2021. CC BY 4.0 License.

\section{(c) (i)}

Comparing the two polarizations, we observe a higher negative offset in EOS detection for HH (Fig. 8b), but slightly lower overestimation of permanently snow-free areas (Fig. 8a). As the ROC analysis in Fig. 7cf indicates, the $t$ values for the best results dependent on the used polarization and the observed year. The ROC reaches higher values in 2018 compared to 2017 (Fig. 7cf). The optimal value for $t$ differs between the years with higher values found in 2018 (e.g. for HV from 3 to $4 \mathrm{~dB}$ in 2017 to 4 to $5 \mathrm{~dB}$ in 2018; Fig. 7cf). The increase of the optimal threshold is higher in HH than in HV (Fig. 7cf). Hence, the performance of a global threshold is more robust for HV. We used the global parameter configuration that shows the best ROC response for further analysis. This is reached with HV polarization and a threshold of $4 \mathrm{~dB}$ (Fig. 7cf). The resulting layer composites of EOS, permanently snow-free and perennial snow for this configuration are shown in Fig. 9.

The temporal evolution of confusion matrix parameters (Fig. 10ab) shows that overall accuracy is always above $75 \%$ and in more than half of the cases above $90 \%$. The lowest overall accuracy occurs during the melt period, when melt is the strongest and the decrease in SC is the highest. Whereas in 2017, FP and FN are occurring during early melt season, in 2018 mostly FN during late melt is observed. The comparably high proportion of FP responses (14.6\%) in 2017 on DOY 177 (Fig. 10a) is caused by a late snowfall event about the beginning of July undetected in the S-1 dataset. As we observe predominantly FN almost throughout all observations, SC is overall rather underestimated by the S-1 product. An underestimation of early-season SC induced by an overestimation of permanently snow-free areas (Fig. 9ab, 10a) is observed in 2017, whereas in 2018 the observed underestimation of late-season SC (Fig. 10b) as well as perennial snow (Fig. 9cd) is caused by the temporal offset in EOS detection (Fig. 8b). This indicates that a global threshold of $4 \mathrm{~dB}$ might be slightly too high for 2017 and slightly too low for 2018, which is consistent with the ROC analysis (Fig. 7cf). For the EOS product, a $\mathrm{R}^{2}$ score of 0.41 ( $\mathrm{p}<0.001$ ), a RMSE of 13.5 days and a MAE of 9.4 days is observed. The regression density plot in Fig. 10c shows the correlation and the histogram plot in Fig. 10d shows the range of temporal difference in days between the two datasets. Within \pm 2 days, \pm 5 days and \pm 11 days, $21 \%, 47 \%$ and $72 \%$ of all pixel-wise EOS dates are detected. The mean (-3.1 days) and the median value (-4 days) of the histogram are slightly negative, which is consistent with the observed negative offset in EOS detection (Fig. 8b).

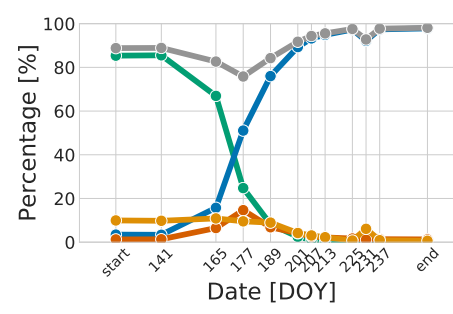

(a)

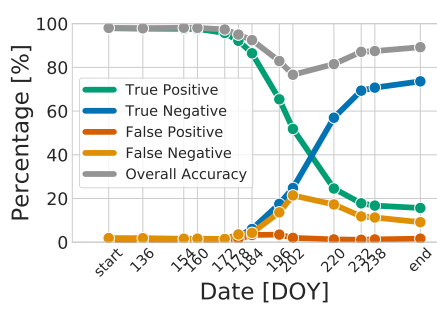

(b)

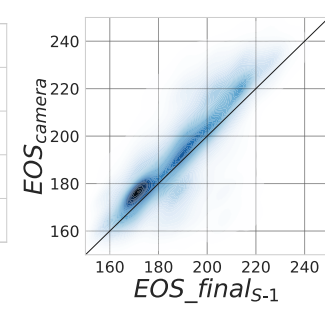

(c)

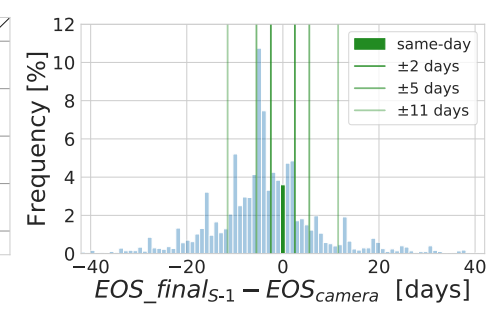

(d)

Figure 10. $(a, b)$ Temporal evolution of true positive, false positive, true negative and false negative as well as overall accuracy of the snow cover maps of the year (a) 2017 and (b) 2018. Overall accuracy is always above $75 \%$ and in more than half of the cases above $90 \%$. Generally, false negative responses or underestimation of snow cover is dominant. False positive responses or overestimation occurs mostly in 2017 around DOY 177. (c) Correlation between EOS detection from S-1 time series approach and time lapse imagery. (d) distribution of temporal offsets in EOS. Highlighted are used time ranges corresponding to 0.5, 1 and 2 Sentinel-1 revisits. 
https://doi.org/10.5194/tc-2021-78

Preprint. Discussion started: 13 April 2021

(c) Author(s) 2021. CC BY 4.0 License.

(c) (i)

\section{Discussion}

\subsection{Influence of SC fraction and snow properties on SAR backscatter intensity}

We observe a distinct seasonal behaviour in S-1 C-band backscatter intensity with a clear decrease during early melt, reaching a minimum just prior to the onset of melting, followed by a constant increase towards the EOS. This is consistent with findings in Lievens et al. (2019) and Marin et al. (2020). According to our observations, this development, which is found in both polarizations (Fig. 6a), is driven by changes of the snowpack, e.g. increased surface roughness, larger size and number of snow grains, as well as by decreasing fractional SC. About half of the increase in intensity occurs within 10-15 days before the decrease in SC fraction starts (Fig. 6ab). This increase before SOD in HH is probably caused by the higher surface roughness, while larger and denser snow grains likely cause increased volume scattering and an increase in HV intensity. The further increase in intensity along with decreasing SC fraction is almost linear and potentially driven by the increasingly higher proportion of the signal coming from snow-free parts of the pixel and possibly a further alteration of the snowpack (Fig. 6c). This linear increase seems suited to derive SC fraction from SAR backscatter intensity (e.g. Luojus et al. (2006) and Koskinen et al. (2009)); however, such an approach would need to address the strong pre-SOD increase in intensity and effects from changing surface properties underneath the snow, speckle and the viewing geometry, which result in variability of the SAR signal and make the discrimination between snow-free areas and areas with low SC fraction in threshold-based SAR approaches like Nagler's method (Nagler et al., 2016; Nagler and Rott, 2000), as well as in our approach, challenging. These results are of comparably high validity, as the observations have been compared to a high-resolution reference dataset of same-day SC fraction maps derived from orthorectified time lapse imagery.

\subsection{Influence of threshold and polarization on the products}

For the selection of thresholds, we observe two main drivers for SC mapping inaccuracies: (i) increased underestimation of SC during early melt linked to an increased overestimation of permanently snow-free areas with higher $t$ (Fig. 7, 8a); (ii) increased underestimation of SC during late melt linked to an increased offset of earlier EOS detection with lower $t$ (Fig. 7, 8b). For an accurate result, these contrary effects need to be balanced. While using a season-independent global threshold leads to a better performance in HV compared to HH due to the lower absolute seasonal changes in backscatter intensities in HV (Fig. 6a), season-dependent thresholds can produce accurate results in both polarizations. The better global performance of crosspolarization for SC detection is in accordance with other studies applying Nagler's method (Nagler et al., 2016; Thakur et al., 2018), which also indicated better performance of the cross-polarization compared to the co-polarization channel. The lower ROC performance in 2017 compared to 2018 (Fig. 7cf) could be caused by the limited length of the time series or lower overall snow depths. The increase towards higher values of the best fitting $t$ in 2018, which is in accordance with the observed higher seasonal backscatter difference (Fig. 6a), is probably caused by higher overall snow depths observed in 2018 (López-Blanco et al., 2020). Additional in situ reference data could further improve the accuracy of the products by finding a season dependent optimal threshold. However, the threshold can vary about $\pm 1 \mathrm{~dB}$ around the optimum while still giving good results (Fig. $7 \mathrm{cf}$ ) which indicates that used global threshold in HV is applicable. 
https://doi.org/10.5194/tc-2021-78

Preprint. Discussion started: 13 April 2021

(c) Author(s) 2021. CC BY 4.0 License.

\section{(c) (i)}

Further analysis of the products with the global polarization-threshold configuration might be critical, as it is conducted with the same dataset used for identifying this configuration. However, the degree of optimization for the threshold setting is reduced to a minimum with a global threshold instead of training a season dependent threshold. Using $\mathrm{HV}$ and $t=4 \mathrm{~dB}, \mathrm{EOS}$ is detected with a reasonable accuracy within two S-1 observations (Fig. 10cd). Potentially a denser time series incorporating different S-1 orbits could improve the accuracy in snowmelt detection. The SC maps reproduce the overall SC evolution with nine out of ten SC maps above $80 \%$ overall accuracy and more than half above $90 \%$ (Fig. 10ab) while most of the error is due to underestimation of SC. Thereby, our product generates similar accuracies as other latest SC mapping approaches with similar spatial resolution based on optical remote sensing (e.g. Gascoin et al., 2019; Girona-Mata et al., 2019; Piazzi et al., 2019). However, it has to be pointed out that autumn and episodic SC due to snowfall events are not detectable by the proposed approach as only the seasonal decrease of SC is observable and dense vegetation in other study areas might cause increased inaccuracies due to the insensitivity of C-band SAR for snow in forested areas (Nagler et al., 2016; Tsai et al., 2019c).

\subsection{Major advantages of the proposed approach compared to other recent SAR based snow cover studies}

With this new approach multiple advances compared to other recent studies on SAR-based SC detection and the current standard, Nagler's method, are made: (i) we use the entire time series instead of only a few images per year unlike most previous studies (according to Tsai et al., 2019b); (ii) we avoid the manual selection of reference images for Nagler's method (Nagler and Rott, 2000) omits challenges like finding a completely snow-free or dry snow scene as well as a potential deterioration of the reference caused by altered backscatter signals due to perennial snow and firn. Due to the simple backscatter threshold approach, we keep analysis fast and reduce processing capacity compared to the supervised classification approach by Tsai et al. (2019a, c), who additionally calculated interferometric and polarimetric features. Even though the spatial resolution is lower in their approach $(100 \mathrm{~m})$, resulting overall accuracies for likewise low vegetated areas are similar to the observed ones here (Tsai et al., 2019c). Threshold setting must be assessed in more detail to confirm, whether a global threshold is applicable also in other sites and years. However, in order to include mapping of dry SC, no spatial or temporal deterioration of the product is required by incorporating optical data (e.g. like in Nagler et al. (2018) and Snapir et al. (2019)). Instead, it is possible to map wet and dry snow exclusively from a SAR time series. Important hydrological measures like start and end of snowmelt (SOS / EOS) can additionally be derived, whereas the former is not detectable with optical remote sensing data. Potentially, the snow phase detection algorithm by Marin et al. (2020) could be incorporated to further separate melt phases in more detail. Different S-1 orbits could be used to increase the temporal resolution of the product. With the additional possibility to map perennial snow at decent accuracy and with a guaranteed 6-day observation range, many relevant parameters for SC monitoring are detected at a weekly basis by the here proposed approach: SOS, EOS, wet and dry SC, perennial snow and permanently snow-free areas. With this information available at a spatial resolution of $20 \mathrm{~m}$, hydrological models could further use this information to derive additional parameters like snow water equivalent (e.g. based on the approach by Kerr et al. (2013)) or assess the delay of snowmelt runoff due to melt water storage in the snowpack and the soil (Marin et al., 2020; Tsai et al., 2020). Thereby, S-1 SAR time series enhances monitoring of hydrological cascading effects and could be used for a holistic hydrological monitoring of SC from the scale of a single catchment up to pan-Arctic observations. 
https://doi.org/10.5194/tc-2021-78

Preprint. Discussion started: 13 April 2021

(c) Author(s) 2021. CC BY 4.0 License.

(c) (i)

\section{Conclusions}

In this study, we present a fast and simple approach for mapping snow cover (SC) and timing of snowmelt based on Sentinel1 (S-1) synthetic aperture radar (SAR) time series. Using the distinct seasonal signal of backscatter intensity above snow, the approach employs user-defined thresholds based on the seasonal backscatter minimum to (i) identify start and end of the snowmelt (SOS/EOS) as day-of-year (DOY), (ii) detect permanently snow-free areas and perennial snow patches and (iii) derive a SC map of wet/dry snow. EOS and SC are compared to maps derived from aligned and orthorectified terrestrial time lapse imagery providing much higher temporal $(2.5 \mathrm{~m})$ and spatial resolution (1 to 10 days) than the $\mathrm{S}-1$ product.

We compared the seasonal evolution of the SAR backscatter intensity to orthorectified SC fraction maps based on same-day time lapse imagery. We observe that about half of the HH and HV backscatter intensity increase during snowmelt occurs within 10-15 days before the decrease in SC fraction starts. From then onwards, backscatter increases linearly with decreasing SC fraction. Hence, changes in the snowpack (e.g. grain size and number, surface roughness) as well as decrease of fractional SC are drivers for the observed backscatter increase.

The new approach to map SC and snowmelt was tested with HH and HV polarizations and different backscatter intensity thresholds (for $\mathrm{HV}$ from 2 to $8 \mathrm{~dB}$; for $\mathrm{HH}$ from 3 to $10 \mathrm{~dB}$ ) indicating the following major error sources: (i) underestimation of SC during early melt due to an overestimation of permanently snow-free areas caused by parts which do not exceed the selected backscatter threshold (increasing with higher thresholds); (ii) underestimation of SC during late melt as well as perennial snow due to a systematically earlier detection of EOS (increasing with lower thresholds); (iii) neglection of episodic and autumn SC due to snowfall events as only the seasonal decrease of SC is detectable. The variation in the optimum threshold is higher in $\mathrm{HH}$, which causes HV to produce better results with a global threshold. The optimal seasonal threshold value increases in accordance with snow depth. Using a global threshold of $4 \mathrm{~dB}$ with the HV polarization, EOS is correctly assigned to the closest S-1 acquisition for $21 \%$ of the area, while $47 \%$ and $75 \%$ are correctly detected within a period of one and two S- 1 repeat cycles (6 and 12 days). The resulting SC maps are generated with an overall accuracy of always more than $75 \%$ and in more than half of the cases above $90 \%$. A SC product with this spatiotemporal resolution ( $20 \mathrm{~m}-6$ days) is, to our best knowledge, not presented with any other open-data remote sensing approach.

Further improvement could take advantage of the combined use of different S-1 orbits to increase the temporal resolution of the product. Thereby, continuous S-1 snow monitoring could not only improve hydrological and climatological models but also lead to an enhanced understanding of the complex interactions between climate change, SC and the arctic ecosystem.

Code and data availability. Relevant code and data can be made available upon request to SB. All Sentinel-1 data are freely available at https://search.asf.alaska.edu/ (Alaska Satellite Facility, 2020) and https://scihub.copernicus.eu/ (ESA, 2020a) upon registration. In situ data from Zackenberg research area are freely available upon registration at https://data.g-e-m.dk/ (Greenland Ecosystem Monitoring Secretariat, 2020). 
https://doi.org/10.5194/tc-2021-78

Preprint. Discussion started: 13 April 2021

(C) Author(s) 2021. CC BY 4.0 License.

(c) (1)

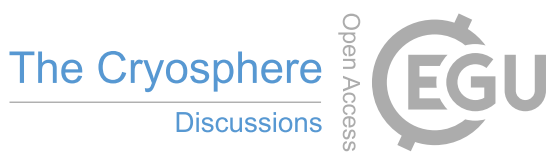

Author contributions. SB conceptualized this study, carried out analysis (methodology, visualization) and wrote the paper. KS assisted with access to GeoBasis data. TU provided resources and supervision. All co-authors assisted during the writing process and critically discussed the content.

Competing interests. The authors declare that they have no conflict of interest.

Acknowledgements. Time lapse imagery and snow cover fraction data from the Greenland Ecosystem Monitoring Programme were provided by the Department of Bioscience, Aarhus University, Denmark in collaboration with Department of Geosciences and Natural Resource 405 Management, Copenhagen University, Denmark. We thank the Education and Research Program by Planet Lab (Planet Team, 2020) for providing free access to PlanetScope satellite imagery for scientific purposes; and the Polar Geospatial Center for providing free access to the ArcticDEM under NSF-OPP awards 1043681, 1559691 and 1542736. 
https://doi.org/10.5194/tc-2021-78

Preprint. Discussion started: 13 April 2021

(c) Author(s) 2021. CC BY 4.0 License.

(c) (i)

\section{References}

Alaska Satellite Facility: Copernicus Sentinel data 2017-18. Retrieved from ASF DAAC, processed by ESA., https://asf.alaska.edu/, last access: 14 April 2020, 2020.

Arslan, A., Tanis, C., Metsämäki, S., Aurela, M., Böttcher, K., Linkosalmi, M., and Peltoniemi, M.: Automated webcam monitoring of fractional snow cover in northern boreal conditions, Geosciences, 7, number: 3 Publisher: Multidisciplinary Digital Publishing Institute, 2017.

Assmann, J. J., Myers-Smith, I. H., Phillimore, A. B., Bjorkman, A. D., Ennos, R. E., Prevéy, J. S., Henry, G. H., Schmidt, N. M., and Hollister, R. D.: Local snow melt and temperature—but not regional sea ice-explain variation in spring phenology in coastal Arctic tundra, Global change biology, publisher: Wiley Online Library, 2019.

Box, J. E., Colgan, W. T., Christensen, T. R., Schmidt, N. M., Lund, M., Parmentier, F.-J. W., Brown, R., Bhatt, U. S., Euskirchen, E. S., Romanovsky, V. E., Walsh, J. E., Overland, J. E., Wang, M., Corell, R. W., Meier, W. N., Wouters, B., Mernild, S., Mlaard, J., Pawlak, J., and Olsen, M. S.: Key indicators of Arctic climate change: 1971-2017, Environmental Research Letters, 14, https://doi.org/10.1088/17489326/aafc1b, number: 4 Publisher: IOP Publishing, 2019.

Brown, R. D. and Robinson, D. A.: Northern Hemisphere spring snow cover variability and change over 1922-2010 including an assessment of uncertainty, The Cryosphere, 5, 219, publisher: Copernicus GmbH, 2011.

Buchelt, S.: georef_webcam V.1.0, https://doi.org/10.5281/zenodo.3899960, 2020.

Buus-Hinkler, J., Hansen, B. U., Tamstorf, M. P., and Pedersen, S. B.: Snow-vegetation relations in a High Arctic ecosystem: Inter-annual variability inferred from new monitoring and modeling concepts, Remote Sensing of Environment, 105, 237-247, number: 3 Publisher: Elsevier, 2006.

Candela, S. G., Howat, I., Noh, M.-J., Porter, C. C., and Morin, P. J.: ArcticDEM Validation and Accuracy Assessment, in: AGU Fall Meeting Abstracts, 2017.

Corripio, J. G.: Snow surface albedo estimation using terrestrial photography, International Journal of Remote Sensing, 25, https://doi.org/10.1080/01431160410001709002, 2004.

Dietz, A. J., Kuenzer, C., Gessner, U., and Dech, S.: Remote sensing of snow - a review of available methods, International Journal of Remote Sensing, 33, 4094-4134, https://doi.org/10.1080/01431161.2011.640964, number: 13 Publisher: Taylor \& Francis _eprint: https://doi.org/10.1080/01431161.2011.640964, 2012.

Dong, C.: Remote sensing, hydrological modeling and in situ observations in snow cover research: A review, Journal of Hydrology, 561, 573 - 583, https://doi.org/https://doi.org/10.1016/j.jhydrol.2018.04.027, 2018.

Elberling, B., Tamstorf, M. P., Michelsen, A., Arndal, M. F., Sigsgaard, C., Illeris, L., Bay, C., Hansen, B. U., Christensen, T. R., Hansen, E. S., Jakobsen, B. H., and Beyens, L.: Soil and Plant Community-Characteristics and Dynamics at Zackenberg, in: High-Arctic Ecosystem Dynamics in a Changing Climate, vol. 40 of Advances in Ecological Research, pp. 223 - 248, Academic Press, https://doi.org/10.1016/S00652504(07)00010-4, iSSN: 0065-2504, 2008.

ESA: Sentinel-1: ESA's Radar Observatory Mission for GMES Operational Services, Tech. rep., ESA - European Space Agency, publication Title: ESA SP-1322/1, March 2012, 2012.

ESA: Copernicus Open Access Hub, https://scihub.copernicus.eu/, publisher: European Space Agency, last access: 14 April 2020, $2020 \mathrm{a}$.

ESA: Observation Scenario Archive, https://sentinel.esa.int/web/sentinel/missions/sentinel-1/observation-scenario/archive, publisher: European Space Agency, last access: 08 February 2020, 2020b. 
https://doi.org/10.5194/tc-2021-78

Preprint. Discussion started: 13 April 2021

(c) Author(s) 2021. CC BY 4.0 License.

(c) (i)

445 Farinotti, D., Magnusson, J., Huss, M., and Bauder, A.: Snow accumulation distribution inferred from time-lapse photography and simple modelling, Hydrological Processes, 24, 2087-2097, https://doi.org/10.1002/hyp.7629, number: 15 _eprint: https://onlinelibrary.wiley.com/doi/pdf/10.1002/hyp.7629, 2010.

Gascoin, S., Grizonnet, M., Bouchet, M., Salgues, G., and Hagolle, O.: Theia Snow collection: High-resolution operational snow cover maps from Sentinel-2 and Landsat-8 data, Earth System Science Data, 11, 493-514, publisher: Copernicus GmbH, 2019.

GCOS-WMO: Essential Climate Variables, https://gcos.wmo.int/en/essential-climate-variables, publisher: Global Climate Observing System - World Meteorological Organization, last access: 09 March 2020, 2020.

Girona-Mata, M., Miles, E. S., Ragettli, S., and Pellicciotti, F.: High-resolution snowline delineation from Landsat imagery to infer snow cover controls in a Himalayan catchment, Water Resources Research, 55, 6754-6772, publisher: Wiley Online Library, 2019.

Greenland Ecosystem Monitoring Secretariat: The Greenland Ecosystem Monitoring (GEM) Database, https://data.g-e-m.dk/, publisher: Greenland Ecosystem Monitoring secretariat, last access: 04 March 2020, 2020.

Hansen, B. U., Sigsgaard, C., Rasmussen, L., Cappelen, J., Hinkler, J., Mernild, S. H., Petersen, D., Tamstorf, M. P., Rasch, M., and Hasholt, B.: Present-Day Climate at Zackenberg, in: High-Arctic Ecosystem Dynamics in a Changing Climate, vol. 40 of Advances in Ecological Research, pp. 111 - 149, Academic Press, https://doi.org/10.1016/S0065-2504(07)00006-2, iSSN: 0065-2504, 2008.

Hinkler, J., Hansen, B. U., Tamstorf, M. P., Sigsgaard, C., and Petersen, D.: Snow and Snow-Cover in Central Northeast Greenland, in: High-Arctic Ecosystem Dynamics in a Changing Climate, vol. 40 of Advances in Ecological Research, pp. 175 - 195, Academic Press, https://doi.org/10.1016/S0065-2504(07)00008-6, iSSN: 0065-2504, 2008.

Hock, R., Rasul, G., Adler, C., Cáceres, B., Gruber, S., Hirabayashi, Y., Jackson, M., Kääb, A., Kang, S., Kutuzov, S., Milner, A., Molau, U., Morin, S., Orlove, B., and Steltzer, H.: High Mountain Areas, The Intergovernmental Panel on Climate Change (IPCC), 2019.

Härer, S., Bernhardt, M., and Schulz, K.: PRACTISE-Photo Rectification And ClassificaTIon SoftwarE (V. 2.1), Geoscientific Model Development, 9, 307, number: 1 Publisher: Copernicus GmbH, 2016.

Ide, R. and Oguma, H.: A cost-effective monitoring method using digital time-lapse cameras for detecting temporal and spatial variations of snowmelt and vegetation phenology in alpine ecosystems, Ecological Informatics, 16, 25 - 34, https://doi.org/https://doi.org/10.1016/j.ecoinf.2013.04.003, 2013.

Kankaanpää, T., Skov, K., Abrego, N., Lund, M., Schmidt, N. M., and Roslin, T.: Spatiotemporal snowmelt patterns within a high Arctic landscape, with implications for flora and fauna, Arctic, Antarctic, and Alpine Research, 50, e1415 624, number: 1 Publisher: Taylor \& Francis, 2018.

Kepski, D., Luks, B., Migała, K., Wawrzyniak, T., Westermann, S., and Wojtuń, B.: Terrestrial Remote Sensing of Snowmelt in a Diverse High-Arctic Tundra Environment Using Time-Lapse Imagery, Remote Sensing, 9, https://doi.org/10.3390/rs9070733, number: 7, 2017.

Kerr, T., Clark, M., Hendrikx, J., and Anderson, B.: Snow distribution in a steep mid-latitude alpine catchment, Advances in Water Resources, 55, 17 - 24, https://doi.org/https://doi.org/10.1016/j.advwatres.2012.12.010, 2013.

Koskinen, J. T., Pulliainen, J. T., Luojus, K. P., and Takala, M.: Monitoring of snow-cover properties during the spring melting period in forested areas, IEEE transactions on geoscience and remote sensing, 48, 50-58, publisher: IEEE, 2009.

Lehning, M., Löwe, H., Ryser, M., and Raderschall, N.: Inhomogeneous precipitation distribution and snow transport in steep terrain, Water Resources Research, 44, https://doi.org/10.1029/2007WR006545, number: 7 _eprint: https://agupubs.onlinelibrary.wiley.com/doi/pdf/10.1029/2007WR006545, 2008. 
https://doi.org/10.5194/tc-2021-78

Preprint. Discussion started: 13 April 2021

(c) Author(s) 2021. CC BY 4.0 License.

(c) (i)

Lievens, H., Demuzere, M., Marshall, H.-P., Reichle, R. H., Brucker, L., Brangers, I., de Rosnay, P., Dumont, M., Girotto, M., Immerzeel, W. W., and others: Snow depth variability in the Northern Hemisphere mountains observed from space, Nature communications, 10, 1-12, number: 1 Publisher: Nature Publishing Group, 2019.

Luojus, K. P., Pulliainen, J. T., Metsamaki, S., and Hallikainen, M. T.: Accuracy assessment of SAR data-based snow-covered area estimation method, IEEE transactions on geoscience and remote sensing, 44, 277-287, number: 2 Publisher: IEEE, 2006.

López-Blanco, E., Jackowicz-Korczynski, M., Mastepanov, M., Skov, K., Westergaard-Nielsen, A., Williams, M., and Christensen, T. R.: Multi-year data-model evaluation reveals the importance of nutrient availability over climate in arctic ecosystem C dynamics, Environmental Research Letters, 15, 094 007, https://doi.org/10.1088/1748-9326/ab865b, publisher: IOP Publishing, 2020.

Marin, C., Bertoldi, G., Premier, V., Callegari, M., Brida, C., Hürkamp, K., Tschiersch, J., Zebisch, M., and Notarnicola, C.: Use of Sentinel1 radar observations to evaluate snowmelt dynamics in alpine regions, The Cryosphere, 14, 935-956, https://doi.org/10.5194/tc-14-9352020, number: 3, 2020.

Meddens, A. J., Vierling, L. A., Eitel, J. U., Boelman, N. T., Jennewein, J., and Maguire, A.: Characterizing and evaluating the Arctic Digital Elevation Model product with LiDAR data for spatial modeling, in: 2017 ABoVE Science Team Meeting, 2017.

Meltofte, H. and Rasch, M.: The Study Area at Zackenberg, in: High-Arctic Ecosystem Dynamics in a Changing Climate, vol. 40 of Advances in Ecological Research, pp. 101 - 110, Academic Press, https://doi.org/10.1016/S0065-2504(07)00005-0, iSSN: 0065-2504, 2008.

Meredith, M., Sommerkorn, M., Cassota, S., Derksen, C., Ekaykin, A., Hollowed, A., Kofinas, G., Mackintosh, A., Melbourne-Thomas, J., Muelbert, M. M. C., Ottersen, G., Pritchard, H., and Schuur, E. A. G.: Polar Regions, 2019.

Mernild, S. H., Liston, G. E., and Hasholt, B.: Snow-distribution and melt modelling for glaciers in Zackenberg river drainage basin, northeastern Greenland, Hydrological Processes: An International Journal, 21, 3249-3263, number: 24 Publisher: Wiley Online Library, 2007.

Mott, R., Egli, L., Grünewald, T., Dawes, N., Manes, C., Bavay, M., and Lehning, M.: Micrometeorological processes driving snow ablation in an Alpine catchment, The Cryosphere, 5, 1083-1098, https://doi.org/10.5194/tc-5-1083-2011, 2011.

Mott, R., Gromke, C., Grünewald, T., and Lehning, M.: Relative importance of advective heat transport and boundary layer decoupling in the melt dynamics of a patchy snow cover, Advances in Water Resources, 55, 88 - 97, https://doi.org/https://doi.org/10.1016/j.advwatres.2012.03.001, 2013.

Mott, R., Vionnet, V., and Grünewald, T.: The seasonal snow cover dynamics: review on wind-driven coupling processes, Frontiers in Earth Science, 6, 197, publisher: Frontiers, 2018.

Nagler, T. and Rott, H.: Retrieval of wet snow by means of multitemporal SAR data, IEEE Transactions on Geoscience and Remote Sensing, 38, 754-765, number: 2 Publisher: IEEE, 2000.

Nagler, T., Rott, H., Ripper, E., Bippus, G., and Hetzenecker, M.: Advancements for snowmelt monitoring by means of sentinel-1 SAR, Remote Sensing, 8, 348, number: 4 Publisher: Multidisciplinary Digital Publishing Institute, 2016.

Nagler, T., Rott, H., Ossowska, J., Schwaizer, G., Small, D., Malnes, E., Luojus, K., Metsämäki, S., and Pinnock, S.: Snow Cover Monitoring by Synergistic Use of Sentinel-3 Slstr and Sentinel-L Sar Data, in: IGARSS 2018 - 2018 IEEE International Geoscience and Remote Sensing Symposium, pp. 8727-8730, https://doi.org/10.1109/IGARSS.2018.8518203, iSSN: 2153-6996, 2018.

Niittynen, P., Heikkinen, R. K., and Luoto, M.: Snow cover is a neglected driver of Arctic biodiversity loss, Nature Climate Change, 8 , 997-1001, publisher: Nature Publishing Group, 2018.

Noh, M.-J. and Howat, I. M.: Automated stereo-photogrammetric DEM generation at high latitudes: Surface Extraction with TIN-based Search-space Minimization (SETSM) validation and demonstration over glaciated regions, GIScience \& Re- 
https://doi.org/10.5194/tc-2021-78

Preprint. Discussion started: 13 April 2021

(C) Author(s) 2021. CC BY 4.0 License.

(c) (i)

mote Sensing, 52, 198-217, https://doi.org/10.1080/15481603.2015.1008621, number: 2 Publisher: Taylor \& Francis _eprint: https://doi.org/10.1080/15481603.2015.1008621, 2015.

Pedersen, S. H., Tamstorf, M. P., Abermann, J., Westergaard-Nielsen, A., Lund, M., Skov, K., Sigsgaard, C., Mylius, M. R., Hansen, B. U., Liston, G. E., and Schmidt, N. M.: Spatiotemporal Characteristics of Seasonal Snow Cover in Northeast Greenland from in Situ Observations, Arctic, Antarctic, and Alpine Research, 48, 653-671, https://doi.org/10.1657/AAAR0016-028, number: 4 Publisher: Taylor \& Francis_eprint: https://doi.org/10.1657/AAAR0016-028, 2016.

Pedersen, S. H., Liston, G. E., Tamstorf, M. P., Abermann, J., Lund, M., and Schmidt, N. M.: Quantifying snow controls on vegetation greenness, Ecosphere, 9, e02 309, number: 6 Publisher: Wiley Online Library, 2018.

Piazzi, G., Tanis, C. M., Kuter, S., Simsek, B., Puca, S., Toniazzo, A., Takala, M., Akyürek, Z., Gabellani, S., and Arslan, A. N.: CrossCountry Assessment of H-SAF Snow Products by Sentinel-2 Imagery Validated against In-Situ Observations and Webcam Photography, Geosciences, 9, https://doi.org/10.3390/geosciences9030129, number: 3, 2019.

Planet Team: Planet Application Program Interface: In Space for Life on Earth, https://api.planet.com, publisher: Planet, last access: 12 December 2019, 2019.

Polar Geospatial Center: Public HTTP Data Repository, http://data.pgc.umn.edu/elev/dem/setsm/ArcticDEM/, last access: 08 February 2020, 2020.

Portenier, C., Hüsler, F., Härer, S., and Wunderle, S.: Towards a webcam-based snow cover monitoring network: methodology and evaluation, The Cryosphere, 14, 1409-1423, https://doi.org/10.5194/tc-14-1409-2020, number: 4, 2020.

Porter, C., Morin, P., Howat, I., Noh, M.-J., Bates, B., Peterman, K., Keesey, S., Schlenk, M., Gardiner, J., Tomko, K., Willis, M., Kelleher, C., Cloutier, M., Husby, E., Foga, S., Nakamura, H., Platson, M., Wethington, Michael, J., Williamson, C., Bauer, G., Enos, J., Arnold, G., Kramer, W., Becker, P., Doshi, A., D’Souza, C., Cummens, P., Laurier, F., and Bojesen, M.: ArcticDEM, https://doi.org/10.7910/DVN/OHHUKH, publisher: Harvard Dataverse Version Number: V1, 2018.

Rees, G.: Remote Sensing of Snow and Ice, https://doi.org/10.1201/9781420023749, 2006.

Richards, J. A.: Remote sensing with imaging radar, vol. 1, Springer, 2009.

Salvatori, R., Plini, P., Giusto, M., Valt, M., Salzano, R., Montagnoli, M., Cagnati, A., Crepaz, G., and Sigismondi, D.: Snow cover monitoring with images from digital camera systems, Italian Journal of Remote Sensing, 43, https://doi.org/10.5721/ItJRS201143211, 2011.

Skov, K., Sigsgaard, C., Mylius, M. R., and Lund, M.: GeoBasis - Guidelines and sampling procedures for the geographical monitoring programme of Zackenberg Basic, publication Title: Zackenberg Ecological Research Operations, GeoBasis, 2019.

Small, D.: Flattening gamma: Radiometric terrain correction for SAR imagery, IEEE Transactions on Geoscience and Remote Sensing, 49, 3081-3093, number: 8 Publisher: IEEE, 2011.

Snapir, B., Momblanch, A., Jain, S. K., Waine, T. W., and Holman, I. P.: A method for monthly mapping of wet and dry snow using Sentinel-1 and MODIS: Application to a Himalayan river basin, International Journal of Applied Earth Observation and Geoinformation, 74, 222 230, https://doi.org/https://doi.org/10.1016/j.jag.2018.09.011, 2019.

Solberg, R., Koren, H., Amlien, J., Malnes, E., Schuler, D. V., and Orthe, N. K.: The development of new algorithms for remote sensing

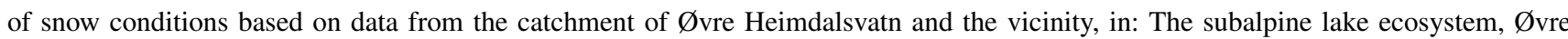
Heimdalsvatn, and its catchment: local and global changes over the last 50 years, pp. 35-46, Springer, 2010.

Storvold, R. and Malnes, E.: Snow covered area retrieval using ENVISAT ASAR wideswath in mountainous areas, in: IEEE International IEEE International IEEE International Geoscience and Remote Sensing Symposium, 2004. IGARSS '04. Proceedings. 2004, vol. 3, pp. 1845-1848, IEEE, Anchorage, AK, USA, https://doi.org/10.1109/IGARSS.2004.1370697, 2004. 
https://doi.org/10.5194/tc-2021-78

Preprint. Discussion started: 13 April 2021

(c) Author(s) 2021. CC BY 4.0 License.

(c) (i)

Thakur, P., Garg, V., Nikam, B., Singh, S., Chouksey, A., Dhote, P., Aggarwal, S., Chauhan, P., Kumar, A., and others: Snow Cover and Glacier

Dynamics Study Using C- and L-Banc SAR Datasets in Parts of North West Himalaya., International Archives of the Photogrammetry, Remote Sensing \& Spatial Information Sciences, 2018.

Thakur, P. K., Aggarwal, S., Arun, G., Sood, S., Kumar, A. S., Mani, S., and Dobhal, D.: Estimation of snow cover area, snow physical properties and glacier classification in parts of Western Himalayas using C-Band SAR Data, Journal of the Indian Society of Remote Sensing, 45, 525-539, number: 3 Publisher: Springer, 2017.

Tsai, Y.-L. S., Dietz, A., Oppelt, N., and Kuenzer, C.: A Combination of PROBA-V/MODIS-Based Products with Sentinel-1 SAR Data for Detecting Wet and Dry Snow Cover in Mountainous Areas, Remote Sensing, 11, 1904, publisher: Multidisciplinary Digital Publishing Institute, 2019a.

565 Tsai, Y.-L. S., Dietz, A., Oppelt, N., and Kuenzer, C.: Remote Sensing of Snow Cover Using Spaceborne SAR: A Review, Remote Sensing, 11, 1456, number: 12 Publisher: Multidisciplinary Digital Publishing Institute, 2019b.

Tsai, Y.-L. S., Dietz, A., Oppelt, N., and Kuenzer, C.: Wet and Dry Snow Detection Using Sentinel-1 SAR Data for Mountainous Areas with a Machine Learning Technique, Remote Sensing, 11, 895, number: 8 Publisher: Multidisciplinary Digital Publishing Institute, 2019c.

Tsai, Y.-L. S., Klein, I., Dietz, A., and Oppelt, N.: Monitoring Large-Scale Inland Water Dynamics by Fusing Sentinel-1 SAR and Sentinel-3 Altimetry Data and by Analyzing Causal Effects of Snowmelt, Remote Sensing, 12, 3896, publisher: Multidisciplinary Digital Publishing Institute, 2020.

Týč, M. and Gohlke, C.: imreg_dft, https://imreg-dft.readthedocs.io/en/latest/, 2014.

Ulaby, F., Long, D., Blackwell, W., Elachi, C., Fung, A., Ruf, C., Sarabandi, K., Zyl, J., and Zebker, H.: Microwave Radar and Radiometric Remote Sensing, 2014.

Ullmann, T., Serfas, K., Büdel, C., Padashi, M., and Baumhauer, R.: Data Processing, feature extraction, and time-series analysis of Sentinel-1 Synthetic Aperture Radar (SAR) imagery: examples from Damghan and Bajestan Playa (Iran), Zeitschrift für Geomorphologie, Supplementary Issues, 62, 9-39, number: 1 Publisher: E. Schweizerbart'sche Verlagsbuchhandlung, 2019.

Westergaard-Nielsen, A., Lund, M., Pedersen, S. H., Schmidt, N. M., Klosterman, S., Abermann, J., and Hansen, B. U.: Transitions in highArctic vegetation growth patterns and ecosystem productivity tracked with automated cameras from 2000 to 2013, Ambio, 46, 39-52, https://doi.org/10.1007/s13280-016-0864-8, number: 1, 2017.

Young, K. L., Brown, L., and Labine, C.: Snow cover variability at Polar Bear Pass, Nunavut, Arctic Science, 4, 669-690, number: 4 Publisher: NRC Research Press, 2018. 